\title{
UNIDAD DE MERCADO Y SUPERVISIÓN ADMINISTRATIVA DE LAS ACTIVIDADES ECONÓMICAS
}

\author{
JAVIER Sola TEYSSIERE \\ Catedrático de Escuela Universitaria de Derecho Administrativo \\ Universidad de Sevilla
}

\begin{abstract}
RESUMEN
La disparidad normativa autonómica viene produciendo distorsiones en el régimen de actividad de las empresas que perjudica su gestión. Frente a ello, sin embargo, la Ley de Garantía de la Unidad de Mercado no dispone medidas positivas de carácter armonizador, estableciendo más bien una estrategia de corte desregulador que incluye disposiciones técnicamente discutibles. Partiendo de ello, el trabajo se centra en el estudio crítico del sistema de determinación de la autoridad competente para la supervisión de las actividades económicas, articulado en base a los conceptos de autoridad de origen, de destino y del lugar de fabricación. Se destaca así que la autoridad de origen debe ser la del primer acceso y que las autoridades de destino deben controlar el ejercicio de las actividades conforme a su propia normativa. El examen arroja que la aplicación del sistema requerirá superar ciertos defectos de técnica legislativa - bastando en algunos casos la vía interpretativa y requiriendo en otros una modificación legal-, así como una estrecha cooperación de las Administraciones públicas implicadas.
\end{abstract}

Palabras clave: unidad de mercado; supervisión administrativa; autoridad de origen/destino; Derecho administrativo económico.

\begin{abstract}
The disparity of regional regulations generates distortions in the economic regime of companies being prejudicial to their management. However, the Act on market unity guarantee does not include positive harmonisation measures, instead establishing a deregulated strategy which includes some technically disputable provisions. Henceforth, the paper is focused on the critical study of the system of determination of the competent authority for the supervising of economic activities, based on the concepts of authority of origin, of destination and the place of manufacturing. It highlights that the authority of origin must be that of the first access and that the authorities of destination must control the exercise of activities in conformity with their own regulation. The examination reveals that the application of the system would require overcoming certain technical legislative defects —an interpretation being sufficient in some cases and a legal modification being required in others- as well as a close cooperation of the public administrations involved.
\end{abstract}

Key words: market unity; administrative supervision; authority of origin/ destination; economic administrative law. 


\section{SUMARIO}

I. CONSIDERACIONES PREVIAS SOBRE LA MOTIVACIÓN Y ESTRATEGIA DE LA LEY DE GARANTÍA DE LA UNIDAD DE MERCADO: 1. Los motivos aducidos por el legislador. 2. La estrategia de la Ley.-II. SUPERVISIÓN ADMINISTRATIVA DE LAS ACTIVIDADES ECONÓMICAS: 1. El esquema de supervisión. 2. Intervención en el momento de acceso a la actividad: A) Control de los requisitos de acceso. B) Determinación de la autoridad de origen. 3. Supervisión del ejercicio de la actividad. 4. Control sobre la producción y requisitos de los productos. 5 . Consideraciones sobre la potestad sancionadora.-III. REFLEXIÓN FINAL.

\section{CONSIDERACIONES PREVIAS SOBRE LA MOTIVACIÓN Y ESTRATEGIA DE LA LEY DE GaRANTÍa DE LA UNIDAD DE MERCADO}

\section{Los motivos aducidos por el legislador}

El preámbulo de la Ley 20/2013, de 9 de diciembre, de Garantía de la Unidad de Mercado (LGUM), declara tener como fin «hacer efectivo el principio de unidad de mercado» ${ }^{1}$. El legislador considera la unidad de mercado como un "principio económico esencial para el funcionamiento competitivo de la economía española» (párrafo primero del preámbulo). La garantía de la unidad de mercado es contemplada así como instrumental al servicio de la finalidad latente de la norma, focalizada en la mejora de la competitividad. En este sentido, la Ley se encuadra en la estrategia económica europea de crecimiento y no es ajena a las reiteradas recomendaciones del Consejo Europeo a nuestro país de eliminar obstáculos al ejercicio de actividades económicas «re-

1 Como es sabido, dicho principio ha sido construido por la jurisprudencia del TC, que identifica su contenido con la garantía de la libertad de circulación y establecimiento de los operadores económicos y los bienes por todo el territorio español, así como la igualdad de las condiciones básicas del ejercicio de actividades económicas, y que, desde el punto de vista competencial, ha delimitado que: a) No se trata de un título competencial del Estado. b) No exige la uniformidad de la normativa administrativa económica, admitiendo diversidad de la normativa autonómica con el límite de no introducir obstáculos al funcionamiento del mercado nacional. c) El Estado puede utilizar sus competencias en materia de bases y coordinación de la planificación general de la actividad económica para garantizar la unidad de mercado. La bibliografía sobre el tema es abundante; entre otras, las monografías de T. DE LA QUADRA-SALCEDO JANINI, Mercado nacional único y Constitución, CEPC, Madrid, 2008; M. CARRASCo DuRÁN, El reparto de competencias entre el Estado y las Comunidades Autónomas sobre la actividad económica, Tirant lo Blanch, Valencia, 2005; V. Tena Piazuelo, La unidad de mercado en el Estado autonómico, Escuela Libre Editorial, Madrid, 1997; E. AlbERTí RovIRA, Autonomía política y unidad económica, Civitas, Madrid, 1995; A. CAlonge Velázouez, Autonomía política y unidad de mercado en la Constitución española de 1978, Universidad de Valladolid, 1988; y el artículo de M. M. FERNANDO PABLO, «Las funciones del principio de unidad de mercado en la jurisprudencia constitucional», Revista Española de Derecho Administrativo, núm. 73, 1992, págs. 29-45. 
sultantes de la existencia de normativas múltiples y superpuestas establecidas por distintos niveles de gobierno ${ }^{2}$. Como tampoco parece ajena su motivación a la tendencia internacional contrastada por los principales indicadores de competitividad realizados por organismos públicos y privados internacionales que apuntan a medidas estructurales liberalizadoras, entre ellas la reducción de cargas administrativas, como determinantes para mejorar dicha competitividad y, con ello, la atracción de inversiones directas ${ }^{3}$.

Dos escollos amenazan dicha estrategia según el legislador: la fragmentación del mercado y el exceso de cargas. Ambos dificultan la actividad de las empresas, por lo que deben ser eliminados, según se dice también en el preámbulo de la Ley. Obsérvese que el primer escollo está directamente relacionado con la actividad pública de ordenación y, más concretamente, su fuente generadora no puede ser otra que la regulación autonómica (y en menor medida la local). El exceso de trabas, por su parte, parece más específicamente vinculado a la actividad administrativa de control y supervisión de las actividades económicas, y cabría imputarlo a cualquiera de las instancias con capacidad regulatoria y de supervisión.

Así, la primera causa justificativa de la LGUM, esgrimida durante su tramitación y abiertamente expresada en su preámbulo, es la afirmación de que en el mercado español subsiste una fragmentación, a la que se achaca una lista de consecuencias perniciosas, tales como que produce un elevado coste para la actividad empresarial, dificulta la competencia efectiva, impide aprovechar economías de escala, desincentiva la inversión y, en general, reduce la productividad, la competitividad, el crecimiento económico y el empleo. Ante la rotundidad de

2 Recomendación del Consejo sobre el Programa Nacional de Reformas de 2012 de España, COM (2012) 310 final, recomendación 8. Asimismo, la Recomendación del Consejo relativa al Programa Nacional de Reformas de 2013 de España, COM (2013) 359 final, insiste en la necesidad de aprobación urgente de la LGUM (recomendación 7), mientras que en la relativa al Programa Nacional de Reformas de 2014, COM (2014) 410 final, el Consejo recomienda garantizar una aplicación rápida y ambiciosa de la LGUM (recomendación 6).

3 Vid. sobre el particular J. C. GARcía dE QuEvedo RuIZ y L. GARCÍA GALlEALTA, «El mercado y otros factores de competitividad para la atracción de inversiones directas extranjeras», Rev. Información Comercial Española, núm. 871, 2013, págs. 77-98, en el que, tras analizar los resultados en general y para España en informes como el Doing Business del Banco Mundial, el The Global Competitiveness Report del Worl Economic Forum o el World Competitiveness Yearbook del IMD y resaltar la importancia de obtener un buen posicionamiento en los mismos como estrategia de atracción de inversiones extranjeras, valoran positivamente en ese contexto las medidas contenidas en el proyecto de LGUM, medidas que no sólo han sido reiteradamente reclamadas por los empresarios españoles, sino también por «la comunidad de inversores extranjeros en España, especialmente por las empresas de EE.UU., Reino Unido y Alemania, entre otros» (pág. 97). 
la afirmación anterior ${ }^{4}$, cabe especular acerca de las fuentes conocidas o presumiblemente manejadas por el legislador para sustentarlas.

La Memoria del Análisis de Impacto Normativo del Anteproyecto de la LGUM, en su parte justificativa, achaca la afirmada fragmentación del mercado nacional, además de al «exceso y dispersión de producción normativa en los sectores económicos», a la existencia de duplicidades, la falta de coherencia y la dispersión normativa en abundantes sectores, citando, entre otros, los de alimentación y bebidas, automóvil, fabricación de cemento, construcción, farmacéutico y un largo etcétera ${ }^{5}$. Resulta significativo que este listado de la Memoria aparece en el mismo orden y coincide en lo esencial con el contenido de un informe de la Comisión de Mercado Interior de la $\mathrm{CEOE}^{6}$, elaborado a partir de los datos suministrados por las diferentes organizaciones territoriales y sectoriales de dicha organización. Ello permite presuponer que el legislador de la LGUM ha tenido en consideración especialmente el aludido informe, así como, probablemente, también otros trabajos y estudios doctrinales elaborados o auspiciados directa o indirectamente en los años precedentes por las organizaciones empresariales ${ }^{7}$. Más cuando en el preámbulo de la LGUM se manifiesta, sin ambages, que la eli-

4 Que ha sido puesta en consideración por S. MuÑoz MACHADO, para quien «no puede decirse seriamente que no exista unidad económica en el Estado español y que su mercado esté fragmentado en tantas piezas como comunidades autónomas», tildando dicha afirmación de exagerada, a la vez que critica que el legislador haya asumido apriorísticamente la pretendida fragmentación del mercado como una aseveración de certeza probada para «montar a partir de ella una regulación que posiblemente sea del gusto de algunos grupos políticos o empresariales pero de dudosa necesidad y utilidad». "Sobre el restablecimiento legal de la unidad de mercado», Revista Española de Derecho Administrativo, núm. 163, 2014, pág. 16.

5 Pero no acompaña explicación o referencia alguna a la fuente de la que se obtienen dichos resultados. Vid. la Memoria citada, de 24 de enero de 2013, págs. 9-10.

6 Informe titulado Inventario de las distorsiones de la unidad de mercado existentes en España, que fue elevado a la CORA. Hemos consultado la actualización de 15 de noviembre de 2012 de dicho informe. Nótese que la Memoria del Análisis de Impacto Normativo citada es de enero de 2013. Vid. un comentario del informe aludido, así como la descripción de otros ejemplos de "distorsión», en B. AguILERA SÁnchEZ-GARRIDO, "De los aspectos teóricos a los aspectos prácticos de la unidad de mercado», Rev. Información Comercial Española, núm. 871, 2013, págs. 107-113. La línea de trabajo inaugurada por el citado informe ha tenido continuidad en el marco más formal de un Convenio de Colaboración firmado en mayo de 2013 entre el Ministerio de Hacienda y Administraciones Públicas y las organizaciones CEOE y CEPYME, fruto del cual se ha generado otro informe titulado Las cargas administrativas soportadas por las empresas españolas derivadas de la fragmentación del mercado interior, hecho público a finales de 2013, coincidiendo con la promulgación de la LGUM (ambos informes están disponibles en www.ceoe.es).

7 Vid., por ejemplo, la ob. col. Marco regulatorio y unidad de mercado, de la serie «Libro Marrón», editada por el Círculo de Empresarios, Madrid, 2006; o el posterior informe del mismo Círculo de Empresarios titulado Administraciones Territoriales: propuestas para la mejora de la eficiencia y de la unidad de mercado, Madrid, 26 de abril de 2011 (disponible en http://circulodeempresarios.org/es/publicaciones). Asimismo, la ob. col. La unidad de mercado en la España actual, editada por el Instituto de Estudios Económicos, Madrid, 2010. 
minación de obstáculos y trabas derivados del incremento de regulación "ha sido una de las principales demandas que los operadores económicos han venido trasladando en los últimos años».

Ciertamente, también ha contado el legislador de la LGUM con informes previos relevantes de otras instituciones públicas. Así, la Memoria del Anteproyecto, en su apartado de análisis de impacto sobre la competencia, se apoya asimismo en el criterio de la antigua Comisión Nacional de la Competencia, que ha venido llamando la atención reiteradamente sobre los problemas que la existencia de una excesiva dispersión normativa viene provocando en términos de segmentación del mercado y de pérdida de eficiencia, recomendando en ocasiones actuaciones tendentes a la homogeneización de requisitos ${ }^{8}$. Por otra parte, cabe aludir a un relevante informe elaborado por la Agencia Estatal de Evaluación de las Políticas Públicas y la Calidad de los Servicios (AEVAL), a requerimiento del Consejo de Ministros de un «diagnóstico sobre las posibles diferencias regulatorias y procedimentales existentes en los distintos ámbitos territoriales y sus efectos sobre la unidad de mercado»" ${ }^{9}$ Por último, otra fuente relevante de información sobre la realidad del problema de la dispersión normativa ha debido seguramente venir de la mano del Plan de Racionalización Normativa, que, junto con la aprobación de la propia LGUM, forma parte del llamado Programa de Unidad de Mercado ${ }^{10}$.

8 Vid., como botón de muestra, el Informe sobre el funcionamiento del mercado de mantenimiento de ascensores en España (2011), págs. 78-79 y 84. También, el Informe sobre las relaciones entre fabricantes y distribuidores en el sector alimentario (2011), pág. 166, o el Informe sobre los Colegios Profesionales tras la transposición de la Directiva de Servicios (2011), págs. 20 y 94 (todos ellos disponibles en http://www.cncompetencia.es).

9 La Orden TAP/700/2011, de 17 de marzo, publica el Acuerdo del Consejo de Ministros de 4 de marzo de 2011 que acordó incluir en el Plan de Trabajo para la AEVAL el encargo mencionado, fruto del cual es el informe Evaluación de las trabas administrativas para la creación de empresas. Segundo informe sobre los trámites administrativos para la creación de empresas, Ministerio de Hacienda y Administraciones Públicas y AEVAL, 2012 (disponible en http://www. aeval.es). Dicho estudio empírico, que toma como referente varios tipos de empresas de características predefinidas pertenecientes a diversos sectores, pone de manifiesto la existencia de significativas diferencias procedimentales y de gestión administrativa (costes de transacción) que comportan asimismo una elevada variabilidad, tanto en los tiempos de tramitación como en los costes económicos, para el establecimiento de muchas de las empresas estudiadas, según el territorio de implantación del establecimiento; vid. especialmente págs. 154-158 y 195-196.

10 Dicho Programa era una de las medidas de reforma estructural incluidas en la Estrategia Española de Política Económica, aprobada por el Gobierno en septiembre de 2012, sustentado en tres ejes: a) la aprobación de una ley de garantía de la unidad de mercado; b) la «identificación, evaluación y modificación, en su caso, de la normativa que afecte a la unidad de mercado en cada uno de los ámbitos competenciales y sectoriales»; c) el desarrollo de sistemas de cooperación administrativa y de resolución de conflictos para la aplicación práctica de la unidad de mercado (pág. 54). La ejecución del segundo eje, ya bajo la denominación de Plan de Racionalización Normativa, emulando el proceso identificativo seguido para la transposición de la Directiva de Servicios, se desarrolla a través de un amplio proceso 
La segunda de las causas justificativas de la LGUM está más enfocada en el exceso de regulación y de cargas administrativas, lo que añade, a nuestro juicio, un matiz que explica en parte la estrategia desregulatoria seguida por el legislador de la LGUM, como se verá en el siguiente apartado. La Memoria de Impacto Económico del Anteproyecto de LGUM se centra principalmente en esta última cuestión, destacando las potenciales bondades de la reducción de cargas que, se pronostica, conllevará la puesta en práctica de la Ley. Así, partiendo de un estudio sobre la progresión de la producción normativa autonómica en el período 1978-201111 y apoyándose en diversos estudios doctrinales que relacionan la intensidad regulatoria con la productividad e innovación ${ }^{12}$, así como el impacto macroeconómico que conlleva una reducción de cargas administrativas ${ }^{13}$, se prevé en dicha Memoria un crecimiento del PIB del 1,52\% como consecuencia de la implantación de las medidas previstas en la LGUM $^{14}$.

participativo de los distintos Ministerios y las Administraciones territoriales suministrando información a través de una aplicación informática específica, con las correspondientes fases de identificación, evaluación y, en su caso, modificación de la normativa que se considere afectada. Según los últimos datos disponibles (abril de 2014), en una primera fase fueron identificadas más de 6.400 normas, que, tras ser objeto de evaluación, se han reducido a unas 2.700 normas que podrían estar afectadas. La fuente de estos datos es un documento titulado Plan de Racionalización Normativa, disponible en la web del Consejo de Unidad de Mercado, que contiene una presentación informativa a unas Jornadas sobre el Programa de Garantía de la Unidad de Mercado celebradas en abril de 2014. Lamentablemente, la información original se nos comunicó que no era accesible. A falta de datos originales, puede verse sobre el particular el artículo de M. Álvarez SuÁreZ y B. PÉREZ RAPOSO, «El programa de Trabajo de Unidad de Mercado: El Plan de Racionalización Administrativa como ejercicio de buena regulación económica», Rev. Información Comercial Española, núm. 871, 2013, págs. 115-125.

11 Incluyendo una tabla demostrativa que cuantifica en 10.261 el número de normas aprobadas por el Estado y las CC.AA., sólo en 2011 (pág. 28 del documento). Puede verse a este respecto el trabajo de F. Marcos, J. Santaló y A. SÁncheZ-Graells, «Measuring regulatory intensity by the Spanish Regions (1978-2009)», InDret, Revista para el Análisis del Derecho, núm. 4/2010, en el que los autores realizan un cómputo del número de páginas publicadas anualmente por los distintos boletines oficiales en el período considerado (considerando este dato relativamente significativo, dado que no discrimina entre disposiciones y demás actos, anuncios, etc., contenidos en los mismos) y también el número de marginales y páginas contenidos en la base de datos de legislación Aranzadi.

12 Así, A. ZÁRATE-MARco y J. VALLÉs-GiMÉNEZ, «The cost of regulation in a decentralized context: the case of the Spanish regions», European Journal of Law and Economics, núm. 33, 2012, págs. 185-203; y F. MARcos y J. SANTALó, Regulation, innovation and productivity, IE Business School Working Paper, 15/7/2010.

13 P. LóPEZ, A. Estrada y C. THOMAS, «Una primera estimación del impacto económico de una reducción de las cargas administrativas en España», Boletín Económico (Banco de España), núms. 7-8, 2008, págs. 81-92; y G. M. GELAUF y A. M. LeJour, Five Lisbon Highlights: The Economic Impact of Reaching these Targets, CPB Document 104, 2006.

${ }^{14}$ Memoria del Análisis de Impacto Normativo..., cit., págs. 27-34. Para una explicación sobre dicha evaluación, vid. P. MÁs RodríGUEZ y C. HERRERo GARCíA, «Impacto macroeconómico de la profundización en la unidad de mercado", Rev. Información Comercial Española, núm. 871, 2013, págs. 65-75. 
Efectivamente, la doctrina económica citada en la Memoria, así como otra que se ha ocupado de esta misma materia, coinciden en destacar la sobreabundancia regulatoria como problema o la necesidad de mejorar la calidad de la misma ${ }^{15}$. Incluso a veces destacando dichos problemas por encima del de la aludida fragmentación del mercado debida a la disparidad normativa ${ }^{16}$.

El examen de la documentación descrita y de los supuestos que se vienen presentando a la Secretaría del Consejo para la Unidad de Mercado (en adelante, SECUM) vía reclamación o procedimientos de información de los artículos 26 o 28 de la LGUM permite afirmar, en nuestra opinión, la existencia real y objetiva de disparidad de requisitos para las mismas actividades económicas según el territorio, dispuestos por las distintas normas autonómicas ${ }^{17}$. Aunque ello se produce en un número significativo de casos, no cabe derivar de ello su alcance generalizado a todas las actividades y sectores, debiéndose valorar, por otra parte, la desigual relevancia de los supuestos exami$\operatorname{nados}^{18}$.

Lo que denuncia el sector es que dicha situación complica la gestión a las empresas de ámbito supraautonómico o que tienen vocación de expandirse. Crítica que, comprensiblemente, prescinde normalmente de valorar la legitimación formal de las normas que sustentan dicha diversidad, centrándose más en destacar los efectos perniciosos que de facto genera en el desarrollo de la actividad. Se estima, pues, que la diversidad normativa interna, aun considerándose constitucional (por respetar el reparto competencial y quedar dentro de los límites admi-

15 Vid. sobre el tema, entre otros, los trabajos de F. BECKER ZUAZUA, «¿Qué hacemos con la regulación?»; A. FERNÁNDEZ DÍAZ, «Descentralización territorial y regulación: una asignatura pendiente»; I. GUTIÉRREZ CARRIZO, «Marco regulatorio y unidad de mercado: una perspectiva desde el análisis económico", incluidos en la ob. col. Marco regulatorio y unidad de mercado, Ed. Círculo de Empresarios, Madrid, 2006.

16 A. Petitbó JuAn destaca la importancia de una regulación eficiente, que asegure la competencia, como mejor instrumento para evitar la ruptura de la unidad de mercado "por encima del debate sobre las diferencias normativas entre territorios». "El espinoso asunto de la defensa de la competencia y la unidad de mercado», en la ob. col. Marco regulatorio y unidad de mercado, Ed. Círculo de Empresarios, Madrid, 2006, págs. 255-283, en especial pág. 257.

17 Los informes de la SECUM se vienen publicando en su web, dentro del portal del Ministerio de Economía y Competitividad: http://www.mineco.gob.es. Por otra parte, la eventual consideración como «informe de parte» de los trabajos de la CEOE no empece lo que se afirma en el texto, dado que en su mayor parte están basados en el examen empírico de diversidad de requisitos establecidos en las normas que se citan y, por ende, fácilmente contrastables. Vid., como botón de muestra, la ficha relativa a la diversidad de requisitos exigidos a las máquinas recreativas tipo B en el informe Las cargas administrativas soportadas..., cit., págs. 20-32.

18 En el informe Las cargas administrativas soportadas..., cit., se lleva a cabo una estimación del ahorro de costes que conllevaría la realización de cada una de las medidas propuestas, que muestra significativas diferencias entre las mismas. 
tidos por el TC que no se consideran vulneración del artículo 139.2), produce un efecto nocivo.

Entendemos que no se trata tanto de la fragmentación o ruptura de la unidad del mercado español, en el sentido de que se imposibilite la circulación de productos o servicios entre los diversos territorios regionales, lo que no parece ajustado a la realidad. Es, más sencillamente, que la disparidad normativa existente produce distorsiones en el lado de la oferta, en cuanto supone para las empresas la necesidad de cumplir distintos requisitos para el acceso o el ejercicio de la misma actividad según los territorios, restando fluidez a la gestión empresarial e implicando duplicidades, superposición de cargas y costes económicos que las empresas no deberían tener que asumir ${ }^{19}$, sin que, frecuentemente, dicha diversidad soporte un elemental test de razonabilidad. Dados los efectos perjudiciales que produce esta situación, parecería oportuno tratar de reducirlos al mínimo y que los casos en los que se considerase necesario mantener singularidades estuvieran suficientemente justificados.

Compartimos, por tanto, el desiderátum de la intervención legislativa, aunque a la vez coincidimos con la opinión mayoritaria de la doctrina que hasta el momento se ha ocupado del tema en la falta de acierto de la técnica empleada para atajar el problema, como seguidamente pondremos de manifiesto.

\section{La estrategia de la Ley}

La constancia de la dualidad de problemas expuesta y de su estrecha correlación tiene su reflejo en la LGUM, que los aborda en el mismo texto legal. Aunque, aparentemente, atendiendo a su título, su objetivo es la "reparación» de la unidad de mercado, en realidad, lo desborda, incluyendo también medidas directamente dirigidas hacia la reducción regulatoria y de cargas administrativas. Así se reconoce en el propio preámbulo de la LGUM cuando, en su parte final, declara que la Ley «aprovecha para seguir impulsando un marco regulatorio eficiente para las actividades económicas que simplifique la legislación

19 Como acierta a indicar la Memoria del Análisis del Impacto Normativo de la LGUM, «sólo el hecho de tener que proceder al estudio de la legislación estatal, autonómica y local para emprender una actividad en España implica un coste considerable», a lo que habría que añadir la necesidad de implantar protocolos de actuación diferentes en ciertos aspectos de la gestión empresarial. Vid., en el mismo sentido, A. FERnÁndEz DíAz, cit., pág. 112, e I. GuTIÉRREZ CARRIZO, cit., pág. 143. 
existente, elimine regulaciones innecesarias, establezca procedimientos más ágiles y minimice las cargas administrativas».

La estrategia de la LGUM, sucintamente descrita, pivota sobre dos aspectos sustantivos que constituyen sus ejes centrales.

En primer lugar, el principio de intervención mínima ${ }^{20}$, encarnado en la Ley por el principio de necesidad y proporcionalidad de las actuaciones de las autoridades que supongan límites a la libertad de empresa, enunciado en su artículo 5 y que tiene su instrumentación en positivo (requisitos de las actuaciones) y en negativo (actuaciones prohibidas) en los artículos 17 y 18, respectivamente.

El problema principal de la nueva regulación es que introduce una severa limitación a la legislación autonómica a la hora de regular los medios de intervención pública sobre las actividades económicas. En concreto, restringe los posibles motivos justificativos del establecimiento de autorizaciones, declaraciones responsables y comunicaciones a unas concretas razones imperiosas de interés general, especialmente constreñidas en el caso de que la medida de intervención a utilizar sea una autorización. El asunto ha sido certera y críticamente explicado por REBOLLO PUiG ${ }^{21}$, para quien esta reducción de las limitaciones que se pueden establecer sobre las libertades económicas no tiene fundamento en el Derecho comunitario ni tampoco en el principio de unidad de mercado que garantiza la Constitución. Para este autor, «no es posible aceptar que una Ley estatal realice esa operación en bloque y para cualquier sector, incluidos los de competencia autonómica exclusiva», por lo que concluye valorando la disconformidad del artículo 5 de la LGUM con la Constitución ${ }^{22}$.

20 Así, J. León SANZ, "La garantía de la unidad de mercado», Rev. Información Comercial Española, núm. 871, 2013, págs. 40-41.

21 A quien sobre este particular nos remitimos: vid. M. Rebollo PUIG, «La libertad de empresa tras la Ley de Garantía de la Unidad de Mercado», Revista Española de Derecho Administrativo, núm. 163, 2014, págs. 23-33 in totum. Si ya la normativa de transposición española fue más allá de lo que exigía la Directiva de Servicios en materia de regulación de los medios de intervención pública sobre las actividades económicas (autorizaciones, declaraciones responsables, comunicaciones), ahora la LGUM la desborda sobradamente, según este autor (pág. 29).

22 Ibídem, pág. 32. Igualmente se pronuncia críticamente sobre el alcance dado al principio de necesidad y proporcionalidad en relación con las autorizaciones G. FERNÁNDEZ FARRERES, «Unidad de mercado y libertades de empresa y de circulación en la Ley 20/2013, de 9 de diciembre», Revista Española de Derecho Administrativo, núm. 163, 2014, en especial págs. 125-131. El Dictamen del Consejo de Estado al Anteproyecto de LGUM, de 26 de junio de 2013, ya puso objeciones a la restricción de razones para la exigencia de una autorización operada por el artículo 17, considerándolas insuficientes y estimando que dicho precepto debería remitirse a las más amplias razones imperiosas de interés general acogidas en el artículo 5. Para el Consejo de Estado, el artículo 17 «no puede reconstituir o reorganizar todo el sistema autorizatorio de las autoridades competentes en materia de actividades competentes» (observación 13). Más explícitamente, el interesante voto particular del consejero permanente 
El segundo aspecto nuclear de la LGUM es la regulación del principio de eficacia, conforme al cual se reconoce efecto en todo el territorio nacional a las actuaciones administrativas de control de acceso a las actividades económicas. Según el artículo 19 de la Ley, cualquier operador que hubiera accedido legalmente a su actividad cumpliendo los requisitos dispuestos en su lugar de origen podrá ejercer su actividad en todo el territorio nacional, debiendo las autoridades de destino asumir la plena validez de dichos requisitos aunque difieran de los propios, e «incluso cuando en la normativa del lugar de origen no se exija requisito, control, cualificación o garantía alguno».

Este constituye uno de los aspectos más polémicos de la Ley, contra el que se dirigen todos los recursos frente a la misma interpuestos ante el Tribunal Constitucional ${ }^{23}$ y ante el que se han mostrado muy críticos diversos órganos consultivos ${ }^{24}$ y una cualificada doctrina ${ }^{25}$. Las críticas suelen además coincidir en un pronóstico: la regulación del principio de eficacia llevada a cabo por la LGUM puede propiciar una competencia regulatoria a la baja o «dumping regulatorio» entre CC.AA ${ }^{26}$, tendente a atraer a

E. Alonso García califica el precepto de «flagrantemente inconstitucional». Por su parte, los recursos de inconstitucionalidad presentados por el Parlamento y el Gobierno catalán se dirigen, entre otros, contra los artículos 5, 17 y 18, que son los que básicamente contienen la regulación expuesta; mientras que el interpuesto por el Gobierno andaluz también, aunque parcialmente, contra los artículos 17 y 18.

23 Los recursos de inconstitucionalidad presentados por el Parlamento y el Gobierno catalán, el Consejo de Gobierno de Andalucía y el Gobierno de Canarias (núms. 1397, 1411, 1454 y 5437 de 2014, respectivamente) se dirigen todos ellos, entre otros, contra los artículos 19 y 20 de la LGUM, que son los que establecen detalladamente la regulación del principio de eficacia.

24 En este sentido, sobre el Anteproyecto de la LGUM, el Informe del Consejo General del Poder Judicial, de 11 de abril de 2013, págs. 21-24, y el Dictamen del Consejo Económico y Social, de 18 de abril de 2013, págs. 8-9 y 14. Aprobada ya la LGUM, sus artículos 19 y 20 son considerados inconstitucionales tanto en el Dictamen 5/2014, de 14 de febrero, del Consell de Garanties Estatutàries de Cataluña como en el Dictamen 193/2014, de 19 de marzo, del Consejo Consultivo de Andalucía.

25 Vid. J. Tornos MAS, «La ley 20/2013, de 9 de diciembre, de garantía de la unidad de mercado. En particular, el principio de eficacia», Revista d'Estudis Autonòmics $i$ Federals, núm. 19, 2014, págs. 163-168, y G. FERNÁNDEZ FARRERES, cit., págs. 133-142; autores ambos que denuncian la inconstitucionalidad de la regulación de dicho principio (pág. 167 y pág. 139, respectivamente). S. MuÑoz MACHADO, cit., pág. 19, considera que una ley del Estado no puede imponer el reconocimiento mutuo de resoluciones basado en una "confianza mutua» $\mathrm{o}$ "reconocimiento implícito» no manifestados por las entidades afectadas, ya que la eficacia extraterritorial de una decisión sólo puede organizarse sobre la base de su reconocimiento por la autoridad de destino.

26 Entre otros, J. Tornos MAs, cit., pág. 160; G. FERnández FArreres, cit., pág. 139; C. PAdRós Reig y J. M. Macías CASTAÑo, «Los instrumentos administrativos de garantía de la unidad de mercado», Revista de Administración Pública, núm. 194, 2014, pág. 129; J. GIFREU FONT, «La impronta de la Directiva de servicios y de la normativa de transposición interna estatal en las técnicas interventoras urbanísticas. Parada y fonda: la Ley de garantía de la unidad de mercado», Revista Vasca de Administración Pública, núm. 98, 2014, págs. 205 y 210; y M. CARLón RuIZ, "Los mecanismos de protección de la unidad de mercado en el seno de la Ley 20/2013», Revista Española de Derecho Administrativo, núm. 165, 2014, pág. 156. 
las empresas de nueva creación a sus territorios. Si ello llegara a materializarse se podría generar, consecuentemente, un efecto discriminatorio inverso, al verse las empresas locales de los territorios con requisitos más estrictos sometidas a la competencia de aquellas que hubieran tenido acceso en otros territorios con menos requisitos o incluso ninguno ${ }^{27}$.

Obsérvese que ninguno de los dos elementos reseñados supone una armonización directa de las normativas autonómicas cuyos efectos distorsionantes la Ley que se proclama de garantía de la unidad de mercado declaradamente se propone corregir. Por el contrario, el legislador evita imponer abiertamente dicha armonización positiva, optando por promover una integración negativa ${ }^{28}$ : lo relevante es la remoción de los obstáculos existentes o potenciales que puedan afectar a la competencia, mientras, solapadamente, se incita a la diversidad (des)regulatoria que puede incluso favorecer dicha competencia.

La Ley, en primer lugar, cercena por abajo las posibilidades regulatorias autonómicas para disponer requisitos de acceso a las actividades económicas, reduciéndolas a un estrecho margen. Las CC.AA. sólo podrán establecer requisitos al acceso del operador dentro de ese margen. En segundo lugar, la entrada en juego del principio de eficacia refuerza la operación desreguladora ${ }^{29}$, en tanto se pronostica que propiciará la opción más liberal para atraer empresas y también probablemente atendiendo a presiones del empresariado local, no dispuesto a sufrir la competencia de otros empresarios que soportan menores cargas.

Realmente, la LGUM no armoniza la regulación de los requisitos de acceso a las actividades económicas ni, mucho menos, los requisitos de

27 Efecto denunciado en el Informe del CGPJ citado (págs. 21-22) y que recoge M. J. Alonso MAS en su crítico y documentado estudio sobre «La eficacia de los títulos habilitantes en todo el territorio nacional y la aplicación de la regla del lugar de origen», en la ob. col. El nuevo marco jurídico de la unidad de mercado. Comentario a la Ley de garantía de la unidad de mercado, dir. M. J. Alonso MAs, Madrid, 2014, págs. 293-352, señalando también que «la unidad de mercado se configura constitucionalmente como límite al ejercicio de las competencias autonómicas; pero, paradójicamente, en la LGUM, para fomentar y hacer efectiva la unidad de mercado, se vaporizan los límites territoriales al ejercicio de dichas competencias» (pág. 305).

28 Vid. al respecto J. LEÓn SANZ, cit., pág. 37.

29 El texto legal evidencia un sesgo desregulador que entronca con la iniciativa europea encarnada en la Directiva de Servicios, igualmente dual, en tanto su objetivo declarado es el impulso de la integración del mercado único pero que también acarrea un propósito colateral de liberalización de la actividad económica y simplificación de cargas administrativas para las empresas de ese amplio sector. La LGUM no tiene vínculo formal con la normativa europea, aunque su preámbulo declara haber tenido en cuenta los principios pertinentes derivados de la jurisprudencia del TJUE, así como la experiencia adquirida con la transposición de la Directiva de Servicios. Es realmente en la normativa de transposición de esta Directiva donde la LGUM tiene sus antecedentes directos. Especialmente evidente es el enlace de la misma con la Ley 17/2009, de 23 de noviembre, sobre el libre acceso a las actividades de servicios y su ejercicio (Ley Paraguas), con la que mantiene concretos puntos de conexión. 
ejercicio de dichas actividades, sobre los que, como explicaremos más adelante, las CC.AA. siguen gozando de amplio margen de disposición. Lo que hace la Ley es liberalizar el acceso a las actividades económicas, vía limitación de requisitos al mismo, fiando a una potencial carrera regulatoria a la baja el que se produzca una uniformización en base a la idea de intervención mínima. Carrera a la baja que tampoco es seguro que se tenga que producir inexorablemente, dada la importancia de otros intereses en juego además del de la atracción de empresas.

La aplicación, por tanto, de los dos elementos centrales ${ }^{30}$ de la Ley no tiene por qué dar como resultado la eliminación de las denunciadas distorsiones del mercado. Cabe pensar en la subsistencia de requisitos diferentes para el acceso a la misma actividad económica dependiendo del territorio, así como de condiciones distintas respecto al ejercicio de la actividad una vez en marcha.

La LGUM se aparta así del objetivo deseable de propiciar una regulación armonizadora de los requisitos de acceso y ejercicio de las actividades económicas, centrándose más en una operación desregulatoria frente a la legislación autonómica ${ }^{31}$.

Junto a los aspectos destacados, la LGUM despliega un conjunto de instrumentos que parecen responder más propiamente a lo que su título parece indicar:

- En primer lugar, contiene medidas encaminadas a evitar la dispersión del sistema normativo en el ámbito económico basadas en la cooperación. Bien ex ante, con carácter preventivo, mediante un sistema de información y valoración previa de la normativa con potencial incidencia en la unidad de mercado (art. 14). Bien a posteriori, a través de la evaluación periódica del impacto de la normativa sobre la unidad de mercado en el seno de las Conferencias Sectoriales.

- En segundo lugar, se ocupa del aparato organizativo, nuevo (Consejo para la Unidad de Mercado) o preexistente (Conferencias Sectoriales), de apoyo a la implantación de la Ley ${ }^{32}$.

30 Ante el interés generado por la polémica regulación de los elementos comentados, ha pasado más desapercibido entre los comentaristas la atención prestada por la Ley al principio de no discriminación (art. 3), que tiene una concreción pormenorizada en distintos apartados del artículo 18.2 y que constituye el remedio a una parte de los problemas planteados.

31 Para Rebollo Puig, cit., pág. 32, dado que el legislador estatal podrá seguir imponiendo límites a la libertad de empresa a través de leyes posteriores, «la novedad y la cuestión crucial están, pues, en el límite que el artículo 5 LGUM impone a los Parlamentos autonómicos», por lo que considera que la LGUM «es sólo una garantía de la libertad de empresa frente a las leyes autonómicas».

32 Sobre el tema puede verse J. OchoA Monzó, «El entramado institucional de la LGUM», en la ob. col. El nuevo marco jurídico de la unidad de mercado. Comentario a la Ley de garantía de la unidad de mercado, dir. M. J. Alonso Mas, Madrid, 2014, págs. 391-400. 
- Por otra parte, como correlato a la regulación del principio de eficacia nacional, establece reglas relativas a la ejecución de la supervisión administrativa en el momento de acceso y sobre el posterior ejercicio de las actividades económicas; aspecto en el que nos centraremos a continuación.

- Por último, instaura mecanismos que podríamos calificar de garantía o reparación, como el recurso administrativo contra actos incompatibles con las libertades de establecimiento o circulación (art. 26), el procedimiento de información de obstáculos a la unidad de mercado (art. 28) y el recurso contencioso-administrativo para la garantía de la unidad de mercado, introducido por la disposición final primera ${ }^{33}$.

En definitiva, a pesar de que la estrategia y la técnica legislativa seguidas no parecen acertadas ni eficaces, sí parece loable el objetivo perseguido, para cuya consecución quizás fuera más adecuado, en nuestra opinión, adoptar actuaciones de integración positiva. En esta línea, ha sugerido TORNos MAS que se podría acudir, en primer lugar, a los instrumentos previstos en la propia LGUM de cooperación en la elaboración de proyectos normativos (art. 14) y a lo que se podría calificar como «armonización paccionada» o de elaboración conjunta de normativas homogéneas en el seno de las Conferencias Sectoriales (art. 12.2). Para el caso de que estas vías no fueran suficientes, «podría pensarse de forma excepcional en recuperar la técnica de la ley de armonización», o recurrir a la competencia transversal estatal del artículo 149.1.13. ${ }^{a}$ de la Constitución "para aquellas intervenciones que sean necesarias por afectar al funcionamiento general de la economía». Como muy claramente ha manifestado este autor: «Lo que el mundo empresarial reclama, y lo que nos parece correcto, no es tanto la supresión de todo requisito previo para el ejercicio de sus actividades económicas cuanto el hecho de que los requisitos exigibles sean razonables, previsibles y que se establezcan con carácter general en una única norma de ámbito estatal» ${ }^{34}$.

33 Sobre los tres mecanismos anteriores pueden verse, respectivamente, los trabajos de A. Casares Marcos, «Mecanismos de protección de los operadores económicos en el ámbito de la libertad de establecimiento y de la libertad de circulación: procedimiento en defensa de los derechos e intereses de los operadores económicos por las autoridades competentes (artículo 26)»; N. BUISÁN GARCía, «Otros mecanismos de protección de la unidad de mercado», y A. SANTAMARÍA PASTOR, «El contencioso de la unidad de mercado», todos ellos en la ob. col. El nuevo marco jurídico de la unidad de mercado, dir. M. J. Alonso Mas, cit.; y el trabajo de SANTAMARÍA, bajo el mismo título, también en Revista Andaluza de Administración Pública, núm. 87, 2013, págs. 51-93. También, C. Padrós Reig y J. M. Macías Castaño, cit., págs. 113-151; y M. CARLóN RuIZ, cit., págs. 147-182.

34 J. ToRnOs MAs, cit., pág. 168; vid. especialmente su desarrollo de la propuesta de recurso a la ley de armonización en págs. 172-175. Incluye asimismo referencias a la posibilidad de recurrir a la competencia estatal del artículo $149.1 .13{ }^{a}$ CE y a las leyes de armonización 


\section{SUPERVISIÓN ADMINISTRATIVA DE LAS ACTIVIDADES ECONÓMICAS}

\section{El esquema de supervisión}

Las Administraciones públicas ejercen una función de control del cumplimiento de las condiciones dispuestas normativamente para el acceso y ejercicio de las actividades económicas. Es a esta faceta de la actividad administrativa de limitación a la que se refiere la supervisión de los operadores económicos que da título al capítulo VI de la LGUM, que se ejercita a través de instrumentos como la exigencia de autorizaciones, declaraciones responsables, comunicaciones, etc., así como la función inspectora, dando lugar eventualmente al ejercicio de la potestad sancionadora.

El artículo 21 de la LGUM establece las reglas de determinación de la autoridad competente para la supervisión de los operadores económicos, lo que sin duda está estrechamente vinculado a la ejecución y efectividad del principio de eficacia de las actuaciones administrativas en todo el territorio nacional. Sin negar dicha conexión, el tema presenta, en nuestra opinión, un interés propio, en la medida que fija unas reglas de distribución del ejercicio de las competencias de control sobre las actividades económicas en general —en consonancia con el ámbito de aplicación de la LGUM- que, por ende, importa examinar. No sólo en tanto que están en vigor, sino en cuanto pueden marcar el camino propicio incluso para el hipotético caso de que se optara en el futuro por los mecanismos de armonización en positivo que se acaban de apuntar, con independencia de la suerte que puedan correr los recursos de inconstitucionalidad interpuestos ${ }^{35}$.

Más concretamente, la LGUM sienta unas reglas de aplicación general dirigidas a garantizar una supervisión administrativa adaptada a los nuevos postulados que la propia Ley incorpora, específicamente el mencionado principio de eficacia en todo el territorio nacional y el

M. J. Alonso MAs, cit., págs. 330-333; esta última ya sugerida en su momento por V. TENA PIAZUELO, «Defensa del principio de unidad de mercado. Riesgo de fragmentación de los mercados a través de la regulación", en la ob. col. Marco regulatorio y unidad de mercado, Ed. Círculo de Empresarios, Madrid, 2006, pág. 354, y por F. MArcos, A vueltas con la «unidad de mercado nacional», Working Paper IE Law School, AJ-177, 2011, págs. 6 y 15.

35 De los recursos de inconstitucionalidad mencionados anteriormente, sólo el presentado por el Consejo de Gobierno de Andalucía recurre los apartados 2 y 3 del artículo 21 LGUM. En su Dictamen 193/2014, el Consejo Consultivo de Andalucía entiende que el artículo 21, apartados 2 y 3, de la LGUM puede ser considerado inconstitucional por menoscabo de las competencias autonómicas de contenido económico previstas en el capítulo II del título II del Estatuto de Autonomía (FJ III.7). 
principio de simplificación de cargas recogido en su artículo 7, tendentes ambos a evitar duplicidades en los casos de potencial concurrencia de varias Administraciones en el ejercicio de las potestades de control.

En principio, con los matices que se señalarán, las aludidas reglas no parecen incongruentes con el sistema de distribución de competencias en materia económica. En consecuencia, pueden resultar de utilidad, una vez despojadas de ciertos defectos de técnica legislativa, a nuestro juicio en parte evitables, e interpretadas en la línea que trataremos de exponer.

Dado que la función de supervisión de la mayoría de las actividades económicas entra dentro del ámbito de las competencias autonómicas, la LGUM pone el foco en establecer las reglas de determinación de la $\mathrm{CA}$ a la que corresponde su ejercicio en los supuestos de empresas que operen en el territorio de más de una de ellas ${ }^{36}$. Obviamente, el supuesto de que no excedan dicho ámbito no reviste problema, así como tampoco los cada vez menos numerosos supuestos en los que la competencia de supervisión es retenida por el Estado, para los que se ha introducido una previsión específica en la disposición adicional primera de la Ley, indicando que en esos casos el principio de eficacia en todo el territorio nacional queda garantizado por la intervención estatal. Por otra parte, la Ley no predetermina la Administración (autonómica, local) competente en cada caso, guardando así el necesario respeto a la distribución interna de competencias dentro de cada CA. Es por ello que se refiere siempre, más neutralmente, a la «autoridad competente del lugar», que vendrá determinada por el régimen de competencias y organización propio de cada Comunidad.

Teniendo en cuenta todo lo anterior, la distribución competencial se articula tomando como base los tres conceptos de autoridad de origen, de destino y del lugar de fabricación. En concreto, el artículo 21.2 LGUM determina a qué autoridad corresponden las funciones ejecutivas de supervisión sobre las actividades económicas:

a) A la de origen, la supervisión de los requisitos de acceso.

b) A la de destino, la supervisión del ejercicio de la actividad.

c) A la del lugar de fabricación, el control de los requisitos de producción y del producto para su uso y consumo.

36 Es inevitable pensar que para ello se ha debido tener en consideración el antecedente que supone las reglas sobre supervisión establecidas por la Directiva de Servicios (arts. 30 y 31) y, en su transposición, por la Ley Paraguas (arts. 29 y 30), para atender los supuestos de operadores establecidos en un Estado miembro que, a su vez, prestan servicios en otros. 
A continuación trataremos de analizar en detalle la problemática que puede generar la aplicación de las anteriores reglas, atendiendo a lo que suele ser el orden cronológico habitual en la actividad administrativa de supervisión en función del objeto de control. Las técnicas administrativas suelen variar según se trate de la supervisión de las actividades en su inicio o ya durante su funcionamiento.

\section{Intervención en el momento de acceso a la actividad}

\section{A) Control de los requisitos de acceso}

De entrada, conviene hacer notar que buena parte de las condiciones y requisitos que la Administración ha de controlar al inicio de una actividad económica suelen estar vinculados al establecimiento físico donde esta se va a desarrollar y que el principio de eficacia nacional no alcanza, razonablemente, a estas actuaciones de control. Parece lógico que sean las Administraciones competentes —autonómicas o, más frecuentemente, locales - del territorio donde esté ubicado físicamente el establecimiento las que vigilen dichos aspectos (urbanísticos, de seguridad, sanitarios, etc.), como así ha sido tradicionalmente.

Es por ello que el artículo 20.4 de la LGUM excepciona la aplicación del principio de eficacia nacional a las actuaciones de supervisión «vinculadas a una concreta instalación o infraestructura física». En consecuencia, las Administraciones autonómicas y locales, según corresponda, mantienen intactas sus funciones de supervisión sobre los establecimientos físicos que, conforme a una fórmula usual de las normas reglamentarias al respecto, abarcan un control al inicio de las actividades, los supuestos de modificación y el caso de cierre.

Cuestión distinta es la relativa a la ordenación o regulación de las técnicas de control y de los requisitos ligados a dichos establecimientos. Aspectos respecto a los que se introducen dos restricciones.

En primer lugar, se han restringido las razones imperiosas de interés general que justifican la exigencia de una autorización como técnica de control respecto a las aludidas infraestructuras e instalaciones físicas, limitándolas a las susceptibles de generar daños sobre el medio ambiente y el entorno urbano, la seguridad o la salud pública y el patrimonio histórico-artístico ${ }^{37}$.

37 Artículo 17.1.b) LGUM y, en los mismos términos, artículo 7.3.a) de la Ley Paraguas, en su nueva redacción introducida por la disposición final segunda de la LGUM. 
En segundo lugar, las autorizaciones o declaraciones responsables «no podrán contemplar» requisitos que no estén específicamente vinculados a las instalaciones o infraestructuras en el caso de que el operador que pretenda su titularidad esté ya legalmente establecido en otro lugar ${ }^{38}$.

Es frecuente que en las regulaciones que establecen el procedimiento de control de acceso a actividades económicas, a través de autorizaciones o declaraciones responsables, se entremezclen requisitos relativos a las instalaciones o infraestructuras con otros que no guardan relación con las mismas. Por razones sistemáticas y de eficacia, parece lógico que continúen con dicho esquema para atender a las situaciones, probablemente más frecuentes, de solicitud de autorización o presentación de declaración responsable por parte de un empresario local para ejercer su actividad en un establecimiento físico situado también en su territorio; sin perjuicio de que, con ocasión de su modificación, introduzcan como excepción el supuesto contemplado por el artículo 20.4 de la LGUM. La no muy afortunada expresión subrayada ("no podrán contemplar») de la Ley, a nuestro juicio, debe interpretarse y aplicarse en el sentido de no exigir los requisitos no vinculados a los establecimientos físicos, como pueden ser los relativos a los elementos subjetivos (constitución formal de la empresa, condiciones relativas a sus gestores o personal) o garantías (seguros, fianzas), en el caso de que el operador que pretenda abrir un nuevo establecimiento físico ya haya accedido a su actividad en otro lugar, cumpliéndose así el resultado pretendido por la LGUM $^{39}$.

De uno de los primeros casos de reclamación presentados ante la SECUM, al amparo del artículo 26 de la LGUM, se puede extraer un ejemplo ilustrativo de lo que se acaba de decir. Muy sucintamente, a un laboratorio de análisis clínicos debidamente autorizado por las autori-

38 Artículo 20.4 LGUM y, en similares términos referidos al prestador de servicios foráneo establecido en España, artículo 7.3.c) in fine de la Ley Paraguas, en su nueva redacción introducida por la disposición final segunda de la LGUM.

39 Así, pongamos por caso, en el supuesto de apertura de una sucursal en Galicia por parte de una empresa establecida legalmente en Asturias, la Administración competente gallega, al tramitar la autorización o declaración responsable, según corresponda, sólo deberá exigir y supervisar los requisitos de la normativa de aplicación (local, autonómica gallega o estatal, según el caso) relativos a los aspectos urbanísticos, medioambientales, de protección del patrimonio, sanitarios o de seguridad vinculados a los elementos objetivos físicos del establecimiento, obviando la exigencia de otros requisitos ajenos a lo anterior. Naturalmente, en dicho procedimiento parece necesaria la comunicación de los datos identificativos de la empresa (entre los que se incluyen los acreditativos de su establecimiento legal en Asturias), a efectos de la posible exigencia de responsabilidades administrativas derivadas de la titularidad del establecimiento físico y también de la eventual función de supervisión sobre el ejercicio de las actividades desarrolladas en la aludida sucursal. 
dades sanitarias de la Comunidad de Madrid le es denegada la autorización para abrir una unidad de obtención de muestras en Badajoz por la Consejería de Salud de Extremadura, no debido al incumplimiento de las características y equipamiento técnico del local (para cuyo control es competente la autoridad regional), sino por incumplir el requisito establecido por la normativa extremeña de estar vinculada dicha unidad a un laboratorio registrado en Extremadura. Esto último, sin embargo, constituye una exigencia no ligada al establecimiento físico que, en consecuencia, la autoridad extremeña debe abstenerse de aplicar ${ }^{40}$.

Lo anterior ha de entenderse aplicable igualmente para el caso de tramitación de un procedimiento sujeto a autorización o declaración responsable en sede municipal instado por un empresario legalmente establecido en el territorio de otro municipio, sean estos de la misma o de distinta Comunidad Autónoma, para el hipotético caso de que sus Ordenanzas ${ }^{41}$ de actividades económicas contemplasen requisitos ajenos a las características de las infraestructuras y equipamientos.

A la vista de lo examinado, la parte de los «requisitos de acceso» potencialmente afectada por la problemática derivada de la aplicación del principio de eficacia nacional queda circunscrita a aquellos elementos no vinculados a los establecimientos físicos; esto es, requisitos relativos a elementos subjetivos concernientes al operador (constitución formal de la empresa), condiciones relativas a sus gestores o personal (cualificación profesional) o garantías (seguros, fianzas), entre otros ${ }^{42}$.

Como es sabido, las normas suelen disponer el deber de mantenimiento en el tiempo de los requisitos aludidos, frecuentemente como una exigencia permanente, por lo que corresponde a la autoridad de origen el control de su cumplimiento al inicio y también durante la actividad.

40 Ello al margen de que el Informe de la SECUM, sobre el que volveremos más adelante, se centra en el aspecto discriminatorio del requisito y en la contravención del principio de eficacia por parte del acto denegatorio, ambos contrarios a la LGUM. El Informe citado es de 28 de abril de 2014 y puede ser consultado en la web de la SECUM. Por su parte, la Consejería de Salud extremeña estimó la reclamación y otorgó la autorización de instalación y funcionamiento de la indicada unidad de obtención de muestras vinculada al laboratorio madrileño.

41 Sobre la problemática que las Ordenanzas municipales que contienen condicionamientos técnicos a productos o actividades generan sobre la unidad de mercado, vid. I. REVUELTA PÉREZ, "La unidad de mercado como límite a las ordenanzas locales», Revista Española de Derecho Administrativo, núm. 146, 2010, págs. 325-357. Y sobre las necesidades y problemas de adaptación de las Ordenanzas municipales a la LGUM, vid. J. J. RASTROLLo SUÁREZ, "Ordenanza municipal y unidad de mercado», en la ob. col. El nuevo marco jurídico de la unidad de mercado, dir. M. J. Alonso MAs, cit., págs. 355-387.

42 Coincidentes, básicamente, con los «requisitos, cualificaciones, controles previos o garantías» a que se refiere el artículo 19.3 LGUM, exigibles a los operadores económicos en el momento de acceso a su actividad. 


\section{B) Determinación de la autoridad de origen}

Cuestión aparte es la relativa a la determinación de la autoridad de origen, atendiendo a la definición que de la misma se hace en el Anexo de la LGUM y a lo dispuesto en la disposición adicional décima de la misma.

En concreto, en una redacción ciertamente confusa, el Anexo establece:

«d) Autoridad de origen: autoridad competente del lugar del territorio nacional donde el operador esté establecido legalmente para llevar a cabo una determinada actividad económica. Se entenderá que un operador está establecido legalmente en un territorio cuando en ese lugar se acceda a una actividad económica y a su ejercicio».

La primera parte de la definición es equívoca pues a nadie se le oculta que un operador puede estar establecido - en el sentido de mantener establecimientos físicos- legalmente en varios territorios autonómicos, con lo que la regla no es operativa para determinar la autoridad de origen, que debe ser sólo una si se quiere que la estructura de asignación de la función supervisora montada por la LGUM tenga una mínima coherencia. La clave, por tanto, debe situarse en la segunda parte, de la que, en nuestra opinión, cabe deducir que la autoridad de origen será la Administración materialmente competente del lugar donde tuvo lugar el primer acceso del operador a su actividad económica y que, por ende, ha debido controlar los requisitos de acceso de dicho operador a la actividad, conforme a la normativa vigente en su territorio.

Esta lectura es coherente con la definición de "establecimiento» contenida en la letra g) del propio Anexo ${ }^{43}$, que viene a vincular el término, en primer lugar, con «el acceso a una actividad económica»; en segundo lugar, con «la constitución y gestión de empresas», recurriendo sólo al final a un residual «en particular por medio de una infraestructura estable».

43 La definición es idéntica a la establecida en el artículo 3.5 de la Ley Paraguas y reza: «Establecimiento: el acceso a una actividad económica no asalariada y su ejercicio, así como la constitución y gestión de empresas y especialmente de sociedades, en las condiciones fijadas por la legislación, por una duración indeterminada, en particular por medio de una infraestructura estable». Definición que se aparta ligeramente de la dispuesta en el artículo 4.5) de la Directiva de Servicios, que omite toda referencia al "acceso» y se centra en el tándem ejercicio-infraestructura: "“establecimiento", ejercicio efectivo de una actividad económica (...) por una duración indeterminada y por medio de una infraestructura estable a partir de la cual se lleva a cabo efectivamente la prestación de servicios». 
Establecido lo anterior, no se entiende bien la introducción vía enmienda presentada por el Grupo Parlamentario Popular, en la tramitación del Proyecto de LGUM en el Senado, de una disposición adicional décima (DA 10. ${ }^{\mathrm{a}}$ ), con el aparente propósito de solucionar "posibles conflictos a la hora de determinar cuál es la autoridad de origen cuando el operador esté legalmente establecido en varios lugares ${ }^{44}$, con el siguiente contenido, que no ha variado en el texto finalmente aprobado:

«Cuando en aplicación de la definición prevista en la letra d) del anexo de esta Ley haya conflicto para determinar cuál es la autoridad de origen o el operador se haya establecido en más de un lugar, elegirá como autoridad de origen la de cualquiera de los lugares en los que se haya establecido y comunicará su elección a las autoridades afectadas. La comunicación producirá efectos a partir de su presentación, no afectando a los procedimientos administrativos iniciados con anterioridad.

Mientras los operadores económicos no hayan efectuado la comunicación de su elección conforme a lo previsto en el primer párrafo de esta Disposición, desde la entrada en vigor de los artículos 20 y 21.2 de esta Ley se considerará que es autoridad de origen la del lugar donde el operador económico ejerce la dirección efectiva de su actividad económica, centraliza la gestión administrativa y la dirección de sus negocios.

Cuando el operador económico no hubiera accedido a esa actividad económica en el lugar donde ejerce la dirección efectiva de su actividad económica, centraliza la gestión administrativa y la dirección de sus negocios, se considerará que es autoridad de origen la del lugar en el que se estableció en primer lugar para llevar a cabo esa actividad económica» ${ }^{45}$.

Para intentar explicar la anterior disposición conviene, asimismo, reproducir el texto de la justificación que acompañó a la enmienda a través de la que fue introducida, que manifiesta:

\footnotetext{
44 Tal como reza el mensaje motivado correspondiente a dicha enmienda. Vid. BOCG (Congreso de los Diputados), Serie A, núm. 56-7, de 26 de noviembre de 2013, pág. 2.

45 Los recursos de inconstitucionalidad presentados por los Gobiernos catalán y andaluz se dirigen ambos contra la disposición adicional décima, entre otros preceptos.
} 
«En el concepto de autoridad de origen, se precisa qué sucede cuando el operador esté legalmente establecido en varios lugares. En este caso, deberá elegir una autoridad entre las de dichos lugares y comunicar su elección al resto. Esta enmienda se considera necesaria para evitar problemas de supervisión y da la libertad al operador de elegir su lugar de origen, entre los diversos en los que haya accedido a la actividad. Para garantizar la necesaria seguridad jurídica, la elección surtirá efectos desde el momento en que se presente» ${ }^{46}$.

Los promotores de la enmienda parecen equiparar lugar de establecimiento y lugar de acceso. Cuando el operador está «legalmente establecido en varios lugares» se considera que ha «accedido a la actividad» tantas veces como lugares en que se haya establecido, de donde se seguiría que un operador accede a la actividad cada vez que decide montar un nuevo establecimiento en otro territorio (u operar legalmente en otro territorio sin establecimiento físico).

Un razonamiento de este tipo rompe con la lógica de la propia Ley, en concreto con el planteamiento que esta hace del principio de eficacia territorial nacional en su artículo 19. Según este, un operador debe cumplir los requisitos de acceso a su actividad establecidos en el lugar donde accede —entendemos que por primera vez - a la misma, que pasa así a considerarse lugar de origen. Ello, a su vez, le habilita para ejercer dicha actividad económica en todo el territorio "mediante establecimiento físico o sin él». La finalidad es, claramente, evitar duplicidades, reduciendo los eventuales controles previos a uno solo en el momento de primer acceso, que, una vez superado, habilita para su ejercicio en todo el territorio. Entender que el operador está accediendo de nuevas a la actividad cada vez que se establece en otro territorio va en contra de la teleología de la Ley y también de su aplicación práctica.

La confusión mostrada por el legislador puede obedecer a que no ha diferenciado entre los requisitos exigibles a cada nuevo establecimiento físico implantado por el operador, que quedará sujeto en ese momento al cumplimiento de los requisitos vinculados al mismo establecidos en el lugar de su ubicación, de aquellos otros de carácter constitutivo, subjetivo o relativos a garantías o fianzas, a los que nos hemos referido anteriormente, que sólo deben ser objeto de control en el momen-

46 BOCG (Senado), núm. 266, de 15 de noviembre de 2013, págs. 167-168. 
to del primer acceso y por la autoridad del lugar donde este se produce. Para que el esquema de supervisión montado por la LGUM sea coherente sólo debe haber una autoridad de origen, determinada, en nuestra opinión, por el lugar donde cronológicamente tuvo lugar el aludido primer acceso.

Por ello, no entendemos que el párrafo primero de la DA $10 .^{a}$ se justifique en parte en la posibilidad de que surjan conflictos a la hora de determinar la autoridad de origen. En nuestra opinión, prescindiendo de su retórica, lo que en este párrafo se está estableciendo al utilizar la disyuntiva «o el operador que se haya establecido en más de un lugar» es, lisa y llanamente, la facultad del mismo de elegir a la carta la autoridad de origen bajo cuya supervisión queda en el futuro. Como, por otra parte, se reconoce sin ambages en la justificación de la enmienda reproducida: «Esta enmienda se considera necesaria para evitar problemas de supervisión y da la libertad al operador de elegir su lugar de origen».

Ello supone desvirtuar el sentido mismo de haber establecido en la propia LGUM el concepto de autoridad de origen y los efectos que esta le atribuye. La autoridad de origen tiene como función principal el control del cumplimiento de los requisitos de acceso de un operador en el momento en que dicho acceso se produce. Para ello, sea a través de un procedimiento de autorización, de una declaración responsable o de una comunicación, normalmente controlará cuestiones tales como los datos de constitución de la empresa y su domicilio, datos de su representante legal, así como, en su caso, datos del o de los establecimientos físicos, cualificación profesional del personal requerida, constitución de garantía, suscripción de un seguro de responsabilidad, etc.; exigiendo paralelamente la tenencia de la documentación acreditativa de los requisitos anteriores que considere necesaria. La Administración actuante, a través de un procedimiento, instruye un expediente administrativo que, normalmente, tiene su expresión final en la inscripción de la empresa en un registro administrativo. Pero otra función anexa de dicha autoridad de origen es la supervisión de que los requisitos que habilitaron para el acceso a la actividad se mantienen en el tiempo (v. gr., mantenimiento de la garantía, validez del seguro) e incluso una labor de actualización (recibir comunicaciones sobre cambios de datos, de la persona representante, etc.), instrumentada normalmente a través del registro correspondiente, que debe mantener viva y actualizada una ficha registral por cada operador inscrito.

La propia LGUM contiene un precepto congruente con el esquema descrito, para el caso de que un operador desarrolle su actividad eco- 
nómica en otro territorio distinto del de acceso y la autoridad competente para supervisar el ejercicio de esa actividad en dicho territorio detecte el incumplimiento de algún requisito de acceso. En este supuesto, la autoridad de destino deberá comunicárselo a la autoridad de origen, en el entendimiento de que esta última es la más apropiada para adoptar «las medidas oportunas, incluidas las sancionadoras que correspondan» (art. 21.3).

Para una mejor comprensión de lo expuesto quizás convenga ilustrarlo a través de un ejemplo. Piénsese en una agencia de viajes que inicia su actividad en Andalucía y posteriormente se expande abriendo establecimientos físicos, además de en todas las provincias andaluzas, en los territorios de las otras dieciséis CC.AA. En un primer momento tendrá que presentar ante la Consejería de Turismo de la Junta de Andalucía (autoridad de origen) una declaración responsable a través de la que deberá aportar sus datos junto con la acreditación del cumplimiento de ciertos requisitos ${ }^{47}$, entre ellos el de haber constituido una garantía de responsabilidad contractual. Tras las comprobaciones y subsanaciones correspondientes, en su caso, la Consejería procederá a inscribir la agencia de viajes en el Registro de Turismo de Andalucía, notificando una resolución a la misma con los datos de inscripción.

Pero ahí no termina la función de control de la autoridad de origen. Posteriormente, le incumbe la supervisión de que dicha agencia de viajes mantiene permanentemente el cumplimiento de los requisitos mencionados. También la actualización constante del asiento registral, lo que, normalmente, se llevará a cabo a través de la presentación de las correspondientes comunicaciones a las que vendrá obligada dicha agencia cuando se produzca un cambio en algunos de los datos exigidos al inicio, como sería el caso de cambio de su representante legal, o se produzcan nuevas circunstancias, como sería la comunicación de apertura de cada nuevo establecimiento. Incluso, en ocasiones, dichas comunicaciones implicarán el control del cumplimiento de nuevos re-

47 En concreto: a) datos de la empresa (si se trata de una sociedad: razón social, datos de la escritura de constitución —número de protocolo, notaría, fecha de inscripción en el Registro-, domicilio, datos de contacto...); b) datos del representante legal (datos personales, de contacto y del título jurídico que habilita para la representación); c) domicilio a efectos de notificaciones; d) nombre comercial inscrito en el Registro de Marcas (requisito exigido por la normativa andaluza de agencias de viajes); e) datos de la actividad (si comercializa on-line solicitan dirección URL) y de la clasificación (en el caso, mayorista-minorista); f) datos acreditativos de haber constituido la garantía de responsabilidad contractual obligatoria (modo - efectivo, aval, otros títulos-, fecha de constitución en la Caja de Depósitos e importe -180.000 euros si es mayorista-minorista-); g) datos acreditativos de haber suscrito el seguro de responsabilidad civil obligatorio (entidad aseguradora, fecha de suscripción, importe de responsabilidad que cubre —mínimo de 900.000 euros-); h) datos del establecimiento principal. 
quisitos, cuya exigencia se hubiera generado por el propio desarrollo de la actividad ${ }^{48}$. De esta forma se mantiene actualizada la información sobre la empresa, lo que, a su vez, facilita la supervisión del cumplimiento de los requisitos exigidos.

Va de suyo que la agencia puede abrir libremente sucursales en el territorio de las demás CC.AA. sin necesidad de presentar nueva declaración responsable ante las autoridades turísticas respectivas, eventual exigencia que sería contraria a lo dispuesto en el artículo 18.2.b) de la LGUM. Estas últimas podrán, eso sí, comprobar que las sucursales que inicien su actividad en su territorio se encuentran cubiertas por la garantía depositada ante la autoridad turística andaluza ${ }^{49}$. Entre otras cosas, para verificar si la garantía es equivalente a la exigida en su propia normativa y, en su caso, exigir una garantía complementaria [art. 18.2.d)].

Como explicaremos posteriormente, las autoridades turísticas de las otras CC.AA. podrán supervisar el ejercicio de la actividad —deberes informativos, disponer de hojas de reclamaciones, etc.- - de las sucursales localizadas en sus respectivos territorios, y si en esa labor detectan la falta de cobertura de la garantía deberán comunicárselo a la autoridad turística andaluza para que esta adopte las medidas correspondientes.

La situación descrita encaja en el esquema previsto en el articulado de la LGUM, sin que haya conflicto para determinar la autoridad de origen. Pero, frente al mismo, se alza inesperadamente la regla del párrafo primero de la DA 10. ${ }^{a}$, en aplicación de la cual parece que nuestra agencia de viajes puede optar por elegir como autoridad de origen a, pongamos por caso, la autoridad turística del País Vasco (donde sólo tiene un establecimiento) con sólo comunicarlo a las «autoridades afec$\operatorname{tadas} »^{50}$.

Ahora bien, ¿basta realmente con una mera comunicación? La respuesta no puede ser sino negativa, pues si así fuera se produciría una situación sorprendente e irresponsable: que la autoridad turística vas-

48 Como es el caso de la acreditación de haber aumentado y depositado el importe de la garantía en 6.000 euros cada vez que la agencia de viajes comunique la apertura de un nuevo establecimiento que exceda de seis, sea cual sea el territorio de implantación de ese nuevo establecimiento.

49 Como señala MuÑoz Machado, en un contexto más genérico, «siempre será necesario acreditar, ante las autoridades de control de destino, los títulos habilitantes de origen...» (ob. cit., págs. 19-20).

50 ¿Deberá comunicar su elección sólo a las Consejerías competentes en materia de turismo del País Vasco y de Andalucía o también al resto de autoridades turísticas autonómicas en cuyos territorios mantenga establecimientos abiertos, en tanto también pueden considerarse «afectadas»? 
ca, que carece de cualquier tipo de expediente respecto a la agencia ${ }^{51}$, pasaría a ser su nueva autoridad de control de los requisitos de acceso, sin posibilidad de facto de ejercer dicho control.

Creemos que el legislador no ha calibrado bien las posibles consecuencias que la aplicación de esta regla, aparentemente simple, implica. Pero dado que la disposición está establecida y en vigor, parece necesario ofrecer una interpretación de la misma lo más conforme posible con las reglas generales y buena práctica administrativas. Por ello, aunque la DA 10. ${ }^{a}$ sólo establece expresamente la necesidad de una comunicación y nada más, entendemos que al menos la comunicación dirigida a la nueva autoridad de origen debería incluir toda la información exigida para el acceso a la actividad de agencia de viajes en el País Vasco, de modo que la autoridad turística vasca pueda generar un expediente y una inscripción en su propio registro administrativo, que le permita posteriormente ejercer su función de supervisión como nueva autoridad de origen. Además de que, en el ejemplo adoptado, la agencia debería cancelar la garantía en Andalucía y depositarla en la Tesorería General del País Vasco. Es decir, proponemos que se debe operar en este caso de modo similar a si se hubiera producido un cambio de domicilio empresarial.

Si la disposición comentada es ya de por sí criticable, los párrafos segundo y tercero de la misma DA 10 . $^{\text {introducen un par de reglas }}{ }^{52}$, aparentemente concatenadas, que terminan de complicar aún más la situación. Así, para el caso de que el operador no hubiera comunicado su elección conforme a la disposición anterior, y a manera de reglas por defecto, se establece:

1. ${ }^{\text {a }}$ Que se considerará autoridad de origen la del lugar donde el operador ejerce la dirección efectiva de su actividad económica ${ }^{53}$.

2. ${ }^{a} \quad$ Ahora bien, si el lugar donde el operador ejerce la dirección efectiva de su actividad económica no es el lugar donde dicho operador accedió a la actividad, se considerará autoridad de origen «la del lugar en el que se estableció en primer lugar», esto es, el lugar donde se produjo el primer acceso ${ }^{54}$.

51 Pues su normativa en la materia establece que las agencias de viajes domiciliadas en otras Comunidades Autónomas y que ejerzan legalmente su actividad en las mismas podrán establecer libremente sucursales en la CA del País Vasco para el ejercicio de su actividad, sin necesidad de presentar declaración responsable (art. 8.1 Decreto 81/2012, de 22 de mayo).

52 Que FERNÁNDEZ FARRERES califica como «un tanto incomprensibles». Vid. su comentario a la DA 10. ${ }^{a}$, en el que critica su deficiente redacción (ob. cit., pág. 137, nota 34).

53 Utilizando un punto de conexión importado del ámbito tributario; en concreto, de la Ley del Impuesto de Sociedades (art. 8).

54 No alcanzamos a apreciar diferencia significativa alguna entre el par de términos «establecerse/acceder», utilizados por el legislador, a los efectos de aplicación de la Ley. En 
Nótese que la regla 1. ${ }^{\mathrm{a}}$ es superflua, al resultar inmediatamente desmentida por la 2. ${ }^{a}$. Efectivamente, la regla $2 .^{a}$ marca preferencia sobre la 1. ${ }^{\mathrm{a}}$, de modo que en el caso de que no coincidan lugar de dirección efectiva de la actividad y lugar de primer acceso prevalece la autoridad del lugar de este último.

Por consiguiente, la regla $1 .^{a}$ sólo sería aplicable al caso en que coincidan el lugar de dirección efectiva de la actividad y el lugar de primer acceso, en cuyo caso el resultado es el mismo: la autoridad de origen será la del primer acceso.

La secuencia de los párrafos segundo y tercero es absurda, pues conduce sólo a un resultado. Por lo que, recapitulando lo anterior, las reglas vigentes para determinar la autoridad de origen, en el caso de que el operador mantenga establecimientos en más de un lugar, son:

1) La elegida por el operador.

2) Mientras no comunique su elección, la del lugar del primer acceso.

En cualquier caso, no queremos dejar de reiterar nuestra crítica a la DA 10. ${ }^{a}$, por razones técnicas, dada su defectuosa redacción, y también por razones de política legislativa. No deja de resultar llamativo que se permita a los empresarios elegir la autoridad que ha de supervisarlos. El afán liberalizador que claramente inspira el grueso del contenido de la LGUM puede resultar positivo en unas dosis aceptables, pero en este punto se ha llegado a un extremo que no lo es. Como hemos señalado anteriormente (ap. I.2), se ha estimado que la regulación del principio de eficacia puede propiciar una competencia de regulación a la baja entre CC.AA. para atraer a las empresas de nueva creación a sus territorios ${ }^{55}$. La DA $10 .^{\text {a }}$ parece estar propiciando un movimiento similar ${ }^{56}$ pero orientado a las empresas ya existentes.

Lo expresaremos abiertamente. En nuestra opinión, la DA $10 .^{a}$ sobra, es innecesaria. El párrafo primero introduce una regla desafortunada que, además, supone el desconocimiento de una buena práctica administrativa elemental. Los dos siguientes, con su deficiente redacción, establecen unas reglas superfluas que complican más que resuelven y añaden una polémica innecesaria. El conjunto, una vez in-

nuestra opinión, deben entenderse como sinónimos en el contexto en que son utilizados. Lo contrario llevaría al absurdo: ¿el operador presenta declaración responsable en una CA, sólo a efectos formales, pero se establece en primer lugar en el territorio de otra?

55 Incurriendo, por cierto, en otro exceso cual es el de reconocer, como regla general, la libertad de ejercicio de la actividad incluso cuando en la normativa del lugar de origen no se exija requisito, control, cualificación o garantía alguno.

56 En el mismo sentido, J. ToRnos MAS, cit., pág. 163, y M. J. Alonso MAs, cit., pág. 346. 
tegrados el artículo 21 y la definición del Anexo, a buen seguro, va a generar problemas en su aplicación.

En conclusión y para terminar con este punto, atendiendo a lo argumentado, entendemos que hubiera bastado con establecer una única regla para la determinación de la autoridad de origen, que debería ser, de manera natural y lógica, la autoridad competente en el territorio donde tuvo lugar el primer acceso a la actividad del operador.

\section{Supervisión del ejercicio de la actividad}

A la vista de lo examinado hasta el momento se habrá notado que el sistema de distribución de la supervisión sobre los operadores económicos establecido por la LGUM pivota sobre un par de conceptos clave, relativos al objeto de supervisión, que es importante distinguir: a) los requisitos de acceso a la actividad, cuyo control se debe producir al inicio de la actividad; b) los requisitos relativos al ejercicio de la actividad económica, cuya supervisión es simultánea a dicho ejercicio, y en los que nos centraremos a continuación.

La normativa, especialmente la reglamentaria, reguladora de las distintas actividades económicas suele contener un conjunto de requisitos, deberes, limitaciones o prohibiciones atinentes al funcionamiento y la gestión ordinaria de la actividad una vez iniciada, que conforman jurídicamente la disciplina de ejercicio de dicha actividad. La supervisión habitual sobre su cumplimiento se instrumenta, principalmente, a través de la vigilancia e inspección o de órdenes singulares, que pueden dar lugar eventualmente al ejercicio de la potestad sancionadora ${ }^{57}$.

57 La Directiva de Servicios, en su considerando 106, especifica que «a los efectos del capítulo sobre cooperación administrativa, el término "supervisión" debe abarcar actividades tales como controles e indagaciones, resolución de problemas, ejecución e imposición de sanciones y las consiguientes actividades de seguimiento». Ciertamente, el ejercicio de la actividad de control puede abarcar la utilización de otros instrumentos como la exigencia de autorizaciones, declaraciones responsables, comunicaciones o deberes de registro cuya ordenación, sin embargo, por parte de las autoridades de destino ha quedado ahora restringida a tenor del artículo 18.2.b) de la LGUM, que dispone: «Serán consideradas actuaciones que limitan el libre establecimiento y la libre circulación por no cumplir los principios recogidos en el Capítulo II de esta Ley los actos, disposiciones y medios de intervención de las autoridades competentes que contengan o apliquen: b) Requisitos de obtención de una autorización, homologación, acreditación, calificación, certificación, cualificación o reconocimiento, de presentación de una declaración responsable o comunicación o de inscripción en algún registro para el ejercicio de la actividad en el territorio de una autoridad competente distinta de la autoridad de origen». Sobre la actividad de inspección, vid. las ponencias y comunicaciones recogidas en La función inspectora, Actas del VIII Congreso de la Asociación Española de Profesores de Derecho Administrativo (celebrado en Alicante, 8 y 9 de febrero de 2013), coord. J. J. DíEz SÁNCHEZ, INAP, Madrid, 2013. 
En nuestra opinión, el operador queda sometido en este punto a la normativa vigente en el territorio donde ejerza su actividad, cuya supervisión corresponde a la autoridad competente en dicho territorio, que, en la terminología de la LGUM, se denomina autoridad de destino. Conviene precisar que, conforme a la definición de "autoridad de destino» establecida en el Anexo de la LGUM, esta es competente para supervisar el ejercicio de la actividad económica llevada a cabo por un operador en su territorio, sea a través de un establecimiento o sin él. La autoridad de destino, obviamente, exigirá y supervisará el cumplimiento de su propia normativa. En definitiva, el operador que ejerza sus actividades en más de un territorio autonómico se verá sometido a la normativa relativa a las condiciones de inicio del lugar donde acceda a la actividad, así como a la normativa relativa al funcionamiento de dicha actividad vigente en el lugar donde ejerza la misma, sea este el de acceso u otro.

Esta lectura no sólo es coherente con el funcionamiento del esquema de supervisión dispuesto por la LGUM, sino que resulta necesaria para que este se ajuste al principio de eficacia territorial de las normas. Una cosa es admitir el efecto extraterritorial del título habilitante para el acceso a la actividad ${ }^{58}$ y otra, bien distinta, admitir que el operador, una vez obtenido este, al ejercer su actividad en otros territorios se rige por la disciplina de la actividad vigente en el territorio donde obtuvo dicho título, como si acarreara una especie de fuero personal itinerante. Esta última lectura, además de resultar inaceptable desde el punto de vista del principio de territorialidad de las normas, resultaría a la vez inoperante puesto que obligaría a los órganos de control de la autoridad de destino a conocer y aplicar una normativa que les es ajena ${ }^{59}$.

58 M. J. ALONSo MAS, cit., ya apuntó que la interpretación coherente con la territorialidad de las normas autonómicas pasaría por distinguir entre «requisitos formales» (relativos a la obtención del título habilitante), respecto a los que el Estado puede determinar su eficacia extraterritorial, y, por otra parte, "requisitos materiales», respecto a los que «la Comunidad de destino sí podría exigir que el producto o servicio posea los requisitos sustantivos exigidos en su propia normativa». No obstante, a continuación duda de que la regulación de la LGUM se pueda interpretar en el sentido por ella misma planteado debido a la lectura que realiza de diversos preceptos de la Ley $(18.2,19,20.1,20.4)$ que conllevan una constante apelación a los «requisitos» como algo distinto a los controles previos, impedirían la exigencia de nuevos requisitos por parte de las autoridades de destino, así como adoptar medidas aunque los productos no cumplan con los requisitos sustantivos de la normativa del lugar de destino (vid. su examen in extenso en págs. 343-345), lo que, en su opinión, «redunda en que la LGUM confiere eficacia extraterritorial asimismo a las normas reguladoras de requisitos sustantivos». Cfr. también M. CARLón RuIZ, cit., pág. 154, quien considera que la LGUM niega a las CC.AA. «la posibilidad misma de ejercer sus competencias sectoriales —ordenadoras y ejecutivas- que afecten a cualesquiera actividades económicas cuando se proyecten sobre operadores económicos que no tengan su "primer establecimiento" en su territorio».

59 Apunta, igualmente, dicha disfunción M. J. Alonso MAS, cit., pág. 348. 
Las autoridades de destino, en el ejercicio de sus potestades de ordenación, pueden establecer requisitos vinculados estrictamente al ejercicio de la actividad, tales como la existencia de hojas de reclamaciones en los establecimientos, exigencias informativas hacia los consumidores y usuarios, condiciones de comercialización de productos o servicios, condiciones de conservación de los productos para su venta, y otras muchas cuyo control ha de ser in situ.

Junto a ello, algunos de los requisitos de tipo subjetivo, normalmente exigidos por la autoridad de origen al inicio de la actividad, pueden tener su equivalente como requisitos de ejercicio sujetos a control en destino ${ }^{60}$, en tanto el operador desarrolle su actividad, permanente u ocasionalmente, en el territorio de otra CA cuya normativa así lo disponga. Piénsese en una empresa de cirugía estética que, al acceder a la actividad en Cataluña, se le exige la acreditación de cualificación de su personal sanitario y que, posteriormente, abre establecimientos en otras CC.AA. Obviamente, será a las autoridades sanitarias de estas últimas a las que les corresponderá controlar in situ el deber de atención a los usuarios por parte de personal cualificado en los establecimientos situados en sus territorios, conforme a su propia normativa y, en su caso, sancionando su incumplimiento, al constituir un requisito de ejercicio.

En tercer lugar, el artículo 18.2.d), cuando considera disconforme con la Ley la exigencia de «requisitos de seguros de responsabilidad civil o garantías equivalentes o comparables en lo esencial en cuanto a su finalidad y a la cobertura que ofrezca en términos de riesgo asegurado, suma asegurada o límite de la garantía, adicionales a los establecidos en la normativa del lugar de origen», está admitiendo a sensu contrario que la autoridad de destino exija una garantía complementaria en dichos supuestos ${ }^{61}$.

Las autoridades de destino pueden establecer, por último, requisitos vinculados a las infraestructuras físicas que mantenga en su territorio el operador que accedió en otro lugar a su actividad, junto a los relacionados con la ocupación del dominio público o cuando el número de operadores sea limitado en función de la existencia de servicios públicos sometidos a tarifas reguladas, también previstos en el artículo 20.4 LGUM.

60 A veces, como ha notado M. J. ALONso MAS, cit., pág. 347, puede que «no resulte sencillo determinar cuándo estamos ante una cuestión atinente al ejercicio de la actividad, y competencia de la autoridad de destino; y cuándo estamos ante un requisito relativo al acceso a la misma o a la fabricación o requisitos del producto».

61 En el mismo sentido, M. J. ALONSo MAS, cit., pág. 345 (nota 63), que asimismo señala el antecedente que tiene este precepto en el artículo 23 de la Directiva de Servicios. 
Desde un punto de vista sustantivo, cabe observar que las normas que establezcan requisitos atinentes al ejercicio de las actividades económicas tienen que observar dos limitaciones.

Por un lado, deben motivar su necesidad en alguna de las razones imperiosas de interés general enumeradas en el artículo 3.11 de la Ley 17/2009, de 23 de noviembre, sobre el libre acceso a las actividades de servicios y su ejercicio, conforme al dictado expreso del artículo 5.1 de la LGUM ${ }^{62}$. Ello supone que los posibles límites al ejercicio de la libertad de empresa sólo podrán sustentarse en un numerus clausus de razones imperiosas de interés general, lo que, como acertadamente ha notado REBOLlo PUiG, deja fuera otras posibles razones que pudieran justificar restricciones a dicha libertad ${ }^{63}$, además de utilizar de forma limitativa una técnica que en el Derecho comunitario, de donde proviene, es abierta y no restringida a una lista cerrada. Conviene notar que el ámbito de posibles justificaciones a límites respecto al ejercicio de las actividades económicas (en cuanto no suele incluir la exigencia de autorizaciones) es más amplio que para el caso de las autorizaciones de acceso, limitadas a razones de orden público, seguridad pública, salud pública o protección del medio ambiente [art. 17.1.a) LGUM].

Por otro lado, dichas normas no deben establecer requisitos considerados contrarios a la LGUM por su artículo 18.2, entre otros: obtención de autorizaciones o presentación de declaraciones responsables en el territorio de la autoridad de destino, exigencia de requisitos de cualificación profesional adicionales a los requeridos en el lugar de origen, o requisitos de seguros de responsabilidad civil o garantías equivalentes o comparables a las exigidas en origen, como se ha señalado.

Finalmente, se observa una laguna técnica que conviene integrar tocante a la definición de autoridad de destino establecida en el Anexo de la Ley, puesta en relación con el contenido del artículo 21. Grosso modo, el reparto establecido por el artículo 21 supone que a la autoridad de origen le corresponde la supervisión de los requisitos de acceso, mientras que a la autoridad de destino le compete la del ejer-

62 Que establece: «Las autoridades competentes que en el ejercicio de sus respectivas competencias establezcan límites al acceso a una actividad económica o su ejercicio de conformidad con lo previsto en el artículo 17 de esta Ley o exijan el cumplimiento de requisitos para el desarrollo de una actividad, motivarán su necesidad en la salvaguarda de alguna razón imperiosa de interés general de entre las comprendidas en el artículo 3.11 de la Ley 17/2009, de 23 de noviembre, sobre el libre acceso a las actividades de servicios y su ejercicio».

63 Rebollo menciona, entre otras, aquellas contenidas en el artículo 38 de la Constitución, como son las derivadas de la «defensa de la productividad», de las «exigencias de la economía general» o de la "planificación», y añade que la Unión Europea nunca ha considerado que sólo las razones imperiosas de interés general pueden justificar restricciones a la libertad de empresa (La libertad de empresa..., cit., págs. 26 y 27). 
cicio de la actividad. Pero la definición de autoridad de destino del Anexo no se limita a decir que esta es la competente en el lugar donde el operador desarrolla el ejercicio de dicha actividad, sino que agrega la circunstancia de que dicho operador esté «legalmente establecido en otro lugar del territorio nacional». Con lo cual la lectura literal de conjunto genera un vacío al no determinar cuál es la autoridad competente para supervisar el ejercicio de la actividad desarrollada por el operador en el mismo territorio donde accedió a la misma, con independencia de que desarrolle también o no dicha actividad en otros territorios. La respuesta, no obstante, parece obvia. Si el operador accede a la actividad en Andalucía y, como será frecuente, posteriormente la ejerce en dicho territorio - con independencia de que la ejerza también en el de Castilla-La Mancha y Extremadura-, será la autoridad andaluza la competente para la supervisión y control del ejercicio de dicha actividad en su ámbito territorial. En la terminología de la Ley, confluirán en la Administración competente andaluza las funciones de autoridad de origen y de autoridad de destino, al margen del inciso señalado de la definición del Anexo. La compartimentación de funciones que, aparentemente en aras de la simplificación, establece el artículo 21, junto con el afán por resaltar en la definición del Anexo la cualidad de autoridad «de destino», dejan en el aire la concreta determinación de la autoridad competente respecto de una situación que ha de ser común.

La argumentación que se ha venido desarrollando en este epígrafe, señalando la autonomía de los requisitos de ejercicio de la actividad económica en relación con los de acceso a la misma, está en línea con la mantenida en alguno de los informes emitidos por la SECUM ante las primeras reclamaciones presentadas vía artículo 26 LGUM.

Así, en el primer caso presentado ante la SECUM, una empresa del sector del juego plantea la contradicción con la LGUM de un reglamento autonómico que establece una prohibición de retransmitir eventos que puedan ser objeto de apuestas a través de los monitores de máquinas auxiliares instaladas en locales distintos de los casinos y salones de juego, pues dichas máquinas ya estaban homologadas en otra CA. El informe de dicha Secretaría de 2 de abril de 2014, ante la falta de pruebas concluyentes, opta por aventurar dos posibles interpretaciones. Interesa destacar la segunda de ellas, en la que se afirma que si la medida autonómica no afecta a la homologación de la máquina (cosa que no considera probada) se estaría ante un requisito de ejercicio exigido a los operadores para la prestación de los servicios especificados y, por tanto, «sujeto a la normativa del lugar donde se ejer- 
ce la actividad económica, en este caso el lugar donde se instalan las máquinas auxiliares» ${ }^{64}$.

La SECUM también considera una medida autonómica denegatoria de un régimen especial de horarios de apertura comercial como «asimilable» a un requisito de ejercicio, por lo que no se ponen en cuestión las posibles diferencias de régimen entre CC.AA. dentro del esquema básico de mínimos fijado por la Ley estatal 1/2004, de 21 de diciembre, de Horarios Comerciales. Pero sí aprovecha la Secretaría su informe para recordar la obligatoriedad de que dichos requisitos de ejercicio respeten los principios de necesidad y proporcionalidad de las actuaciones de las autoridades competentes establecidos en el artículo 5 de la LGUM, cuyo cumplimiento cuestiona en el caso concreto sometido a su informe ${ }^{65}$.

Igualmente es constatable la interpretación que se viene proponiendo en algunos de los denominados «informes de valoración» emitidos por la SECUM en el marco de los procedimientos de información previstos en el artículo 28 de la LGUM. Así, considera que la exigencia de distintos formatos de señalización de la prohibición de fumar en los establecimientos por parte de las regulaciones autonómicas no puede considerarse contraria a la LGUM en la medida en que «pueden entenderse como un requisito de ejercicio de la actividad vinculada a la protección del consumidor», por lo que su regulación corresponde a la autoridad competente del territorio donde la actividad se realice. Similar valoración le merece otro caso en el que se le plantea la diversidad de procedimientos para atender las reclamaciones interpuestas por los consumidores y usuarios por parte de una empresa mediadora de seguros, que la Secretaría no considera contraria a la LGUM. No obstante, en ambos casos, la SECUM reconoce que dichas situaciones podrían estar generando barreras u obstáculos al ejercicio de las aludidas actividades, por lo que termina aludiendo a la activación de medidas de cooperación entre las autoridades implicadas, en el marco del artículo 12 de la LGUM, a través de las Conferencias Sectoriales ${ }^{66}$.

Por otra parte, en el Acuerdo de la Comisión Bilateral de Cooperación Administración General del Estado-Comunidad Autónoma de Ga-

${ }^{64}$ Como se ha indicado anteriormente, todos los informes de la SECUM están disponibles en su web. El citado se titula «Juego. Máquinas de apuestas», y la cita literal es de la pág. 10 del mismo.

65 Vid. págs. 9 y 12 del informe «Comercio-Horarios» de la SECUM, de 25 de noviembre de 2014

66 Vid. informes «Sanidad-Carteles prohibido fumar», de 29 de octubre de 2014, y «Seguros-Hojas de reclamaciones», de 4 de noviembre de 2014, respectivamente, disponibles en la web de la SECUM. 
licia en relación con la LGUM, adoptado de conformidad con lo establecido en el artículo 33 de la Ley Orgánica del Tribunal Constitucional, las partes consideran solventadas sus discrepancias bajo el compromiso de interpretar, sobre el asunto que aquí nos ocupa, que «la referencia del artículo 19.3 a los requisitos, cualificaciones, controles previos, garantías o actuaciones administrativas exigidos conforme a la normativa del lugar de destino que sean distintos a los exigidos al amparo de la normativa del lugar de origen, se refiere exclusivamente a aquellas que estén relacionadas con el acceso a la actividad y no a las condiciones de ejercicio establecidas por la autoridad de destino...» ${ }^{67}$, así como que las autoridades de destino asumirán la validez de los aludidos requisitos, cualificaciones, etc., «exigidos por las autoridades de origen para acceder a una determinada actividad económica, sin que tal asunción alcance el régimen de ejercicio que las autoridades de destino establezcan en su territorio ${ }^{68}$.

Finalmente, interesa señalar algo no por obvio menos relevante: la LGUM tampoco garantiza la eliminación de distorsiones en lo referente a los requisitos de ejercicio de las actividades económicas. Esto es, no contiene medidas que fuercen a las CC.AA. a equiparar los requisitos que condicionan el funcionamiento de las empresas una vez que han accedido a la actividad. Lo único que limita que las CC.AA. mantengan regulaciones dispares en el ámbito de las condiciones de ejercicio de las actividades económicas, al no resultar afectadas por el principio de eficacia nacional, es la prohibición de introducir requisitos que tengan efectos discriminatorios por razón de establecimiento o residencia del operador y aquellas otras prohibiciones que pudieran afectar al ejercicio contempladas en el artículo 18.2 de la Ley.

Así como en relación con las condiciones de acceso se ha podido constatar un comentario generalizado entre la doctrina de que la aplicación del principio de eficacia nacional va a producir de facto una uniformización de las reglas con tendencia hacia las regulaciones de mínimos (race to the bottom $)^{69}$, no es previsible que a las CC.AA. les pu-

67 Cfr. epígrafe e) de la Resolución de 14 de octubre de 2014, de la Secretaría General de Coordinación Autonómica y Local, por la que se publica el Acuerdo de la Comisión Bilateral de Cooperación Administración General del Estado-Comunidad Autónoma de Galicia en relación con la Ley 20/2013, de 9 de diciembre, de garantía de la unidad de mercado (BOE núm. 262, de 29 de octubre de 2014). La cursiva es nuestra.

68 Esto último figura en los mismos términos en el epígrafe c) del Acuerdo de la Comisión Bilateral de Cooperación Administración del Estado-Administración de la Comunidad Autónoma del País Vasco en relación con la Ley 20/2013, de 9 de diciembre, de garantía de la unidad de mercado, publicada por la Resolución de 17 de julio de 2014 de la Secretaría General de Coordinación Autonómica y Local (BOE núm. 195, de 12 de agosto de 2014). La cursiva es nuestra.

69 Vid. supra, ap. I.2. 
diera interesar seguir la misma línea de relajación normativa en relación con las condiciones de ejercicio. Entre otras cosas, porque uno de los principales incentivos ${ }^{70}$ en juego que pudiera estimular lo primero (el tributario derivado de la localización de empresas en el territorio propio, que justificaría su atracción bajo el señuelo de una regulación laxa) se atenúa en la segunda de las situaciones. Es más, cabe elucubrar que, viéndose privadas del control ex ante sobre operadores localizados fuera de su territorio, se decidiera reforzar el control ex post, especialmente en aquellas situaciones en las que la Administración ejerce su labor de supervisión de la legislación protectora de los consumidores ${ }^{71}$.

En definitiva, para la eliminación de distorsiones en este punto se debe apelar de nuevo a las actuaciones de cooperación tendentes a promover la armonización de las normativas autonómicas previstas en la LGUM, así como a su instrumentación a través de títulos estatales (art. 149.1.13. ${ }^{\mathrm{a}}$ y leyes de armonización), ya aludidas anteriormente ${ }^{72}$.

\section{Control sobre la producción y requisitos de los productos}

El artículo 21.2.c) de la LGUM establece una tercera regla al disponer que el control del cumplimiento de la normativa sobre la producción y los requisitos de los productos para su uso y consumo corresponde a las autoridades del lugar de fabricación de los mismos.

La LGUM contiene algunas otras referencias a las actividades de producción, empezando por la encuadrada dentro del mandato general a todas las autoridades de garantizar que se cumplen los principios de la Ley cuando establezcan requisitos exigibles para el ejercicio de las actividades económicas y "para la producción o distribución de bienes» [art. 9.2.b)]. En segundo lugar, considera contrario a la Ley que una autoridad disponga o aplique especificaciones técnicas para la circulación legal de un producto "distintas a las establecidas en el lugar de fabricación» [art. 18.2.e)]. En tercer lugar, reconoce plena eficacia en todo

70 Sin ignorar que, junto al mencionado, se considerará prevalentemente el de posible creación de empleo.

71 Aunque fuera por el rédito político que ello pudiera, teóricamente, reportar. La experiencia indica que hay muy variadas motivaciones que incitan a los poderes regionales a generar la denostada inflación y diversidad normativa, no pareciendo siempre justificadas en la protección de intereses realmente diferenciados. Incluso abundan las críticas señalando a motivaciones más o menos espurias o demagógicas, como la justificación de su gestión frente a los gastos que generan a los ciudadanos (F. BECKER ZuAZUA, cit., pág. 58), el efecto imitación entre CC.AA. o la tendencia a la diferenciación, introduciendo notas distintivas que la diferencien del resto (I. GuTIÉRREz CARRIZO, cit., págs. 137-138).

72 Vid. supra, ap. I.2, y también, en este sentido, M. J. Alonso Mas, cit., págs. 343-344. 
el territorio nacional a las autorizaciones obtenidas de una autoridad competente para la producción o la puesta en el mercado de un bien o producto [art. 20.1.a)].

El análisis de los distintos documentos citados en el primer apartado de este trabajo muestra que no son frecuentes las denuncias relativas a la existencia de distorsiones en relación con los productos. Probablemente, ello se debe a que los aspectos más relevantes de los productos para su uso o consumo, esto es, los referidos a su seguridad y salubridad, suelen estar regulados a nivel nacional, o incluso armonizados a través de Directivas técnicas a nivel europeo ${ }^{73}$.

La actividad de producción conlleva la existencia de unas instalaciones. Si la empresa productora tiene dichas instalaciones en el mismo territorio donde ha accedido a la actividad, la autoridad competente en dicho territorio acumula la supervisión de: a) las condiciones de las instalaciones; b) los requisitos de acceso; c) los procedimientos de fabricación (incluyendo, en su caso, la exigencia de personal cualificado), requisitos de seguridad (que pueden incluir un régimen de autorización u otro control previo sobre productos específicos), estándares de calidad, etc.

No obstante, la empresa puede haber accedido a la actividad en el territorio de una Comunidad Autónoma - que será competente para controlar: b) los requisitos de acceso-y mantener una instalación fabril en otra CA, siendo esta última en dicho caso la competente para supervisar: a) las condiciones de las instalaciones; y c) los procedimientos de fabricación, requisitos de seguridad, etc., mencionados.

En cierto modo, la regla prevista en el artículo 21.2.c), al hacer referencia a actividades de fabricación o producción, está aludiendo a requisitos sobre el ejercicio de las actividades económicas, que corresponde supervisar a la autoridad del lugar donde se produce, esto es, la autoridad de destino, que puede coincidir con la de origen si el acceso legal tuvo lugar en ese mismo lugar.

El último inciso del precepto, «requisitos del producto para su uso y consumo", no obstante, puede resultar equívoco y controvertido, por lo que precisa de alguna aclaración. La autoridad del lugar de fabricación es la competente para supervisar el proceso de la actividad industrial y, como consecuencia, los requisitos exigidos «en origen» a los

73 Sobre el carácter de la regulación e instrumentos de control sobre la seguridad de productos destinados al consumo, vid. la exposición de M. IzQUIERDo CARRASCo, «Protección de la salud y seguridad», en la ob. col. La defensa de los consumidores y usuarios (Comentario sistemático del Texto Refundido aprobado por Real Decreto legislativo 1/2007), dirs. M. REBollo Puig y M. IzQuierdo Carrasco, 2011, en especial págs. 181-185. 
productos, normalmente relativos a su seguridad y calidad, como se ha señalado, para lo que podrá recurrir a la toma de muestras, análisis y controles de calidad y demás técnicas administrativas pertinentes de control de los fabricantes. Al margen de la generalización de los sistemas de autocontrol, los todavía numerosos reglamentos reguladores de productos específicos suelen establecer requisitos relativos a las características del bien en el momento de su fabricación.

Pero conviene no obviar la simultánea vigencia de otros requisitos relativos al "uso y consumo» de los productos, a veces establecidos en los mismos reglamentos específicos aludidos o, más genéricamente, en la diversa legislación comercial o de consumo autonómica, que afectan más bien a los distribuidores que a los fabricantes, en tanto referidos a aspectos vinculados a la comercialización de los productos (etiquetado, conservación y caducidad, presentación, etc.). La supervisión de estos aspectos, también relativos a los «requisitos del producto para su uso y consumo", corresponderá a las autoridades de destino competentes en materia de consumo y comercio donde se produzca el ejercicio de la actividad de comercialización del producto, apartándose, por tanto, de la regla del artículo 21.2.c) LGUM en su referencia a la autoridad del lugar de fabricación. Resulta paradigmático en este punto que el RD 1801/2003, de 26 de diciembre, sobre seguridad general de los productos, que tiene carácter básico, distinga entre los deberes de los productores (art. 4) y de los distribuidores (art. 5) al fijar las reglas en orden a garantizar la seguridad de los productos ${ }^{74}$. Por mucho que el artículo 19.2 LGUM establezca que «cualquier producto legalmente producido al amparo de la normativa de un lugar del territorio español podrá circular y ofertarse libremente en el resto del territorio desde el momento de su puesta en el mercado ${ }^{75}$, habrá de convenirse que tendrá que cumplir los requisitos no sólo de producción, sino también de comercialización, no pudiendo así ofertarse, por ejemplo, en mal estado de conservación o caducado.

Realmente, se trata de uno más de los aspectos confusos de la

74 Por cierto que el artículo 14 del RD citado atribuye a la Administración del Estado la competencia para adoptar las medidas previstas en el mismo (prohibición de suministro, retirada del mercado de productos, etc.), cuya ejecución corresponderá a las CC.AA., "cuando ante un mismo riesgo grave las medidas adoptadas o previstas por las distintas comunidades autónomas resulten divergentes y tal divergencia sea un obstáculo para la garantía de seguridad de los productos, una vez agotados los instrumentos de coordinación y cooperación existentes».

75 Conviene señalar que «la puesta en el mercado de los productos estancos, explosivos, gasóleo profesional y mercancías peligrosas deberá respetar las condiciones de venta establecidas en la normativa estatal aplicable», conforme a lo dispuesto en la disposición adicional segunda de la LGUM. 
LGUM, que, como ya advirtió el Consejo Económico y Social ${ }^{76}$, debería haberse aclarado; sugerencia que no tuvo acogida en el texto final. Y reflejo de la posterior preocupación por las nocivas consecuencias que dicha confusión pudiera causar es el intento de aclaración incluido en el Acuerdo de la Comisión Bilateral de Cooperación Administración General del Estado-Comunidad Autónoma de Galicia en relación con la LGUM, cuando interpreta que los contenidos del artículo 21.2.c) y 3 de la LGUM hacen referencia "exclusivamente a la capacidad de supervisión en origen y respecto a los requisitos de acceso, sin afectar a los requisitos de ejercicio que estén establecidos en cada caso» ${ }^{77}$. Cautela que, aunque es significativa en la línea interpretativa que aquí venimos manteniendo, tampoco es atinada en su intento de aclarar la competencia, en cuanto que sencillamente no es cierto que dichos preceptos se refieran exclusivamente a la supervisión de los requisitos de acceso, pues en ambos se incluye una referencia a los requisitos relativos a la producción y a los productos. El citado Acuerdo realiza así una lectura muy forzada de los preceptos mencionados, toda vez que omite algo que la Ley establece expresamente.

\section{Consideraciones sobre la potestad sancionadora}

En el apartado 3 del artículo 21, que establece una regla muy específicamente vinculada con el ejercicio de la potestad sancionadora, nos parece que faltaría un inciso para que fuera coherente con el texto del apartado segundo del propio artículo, en el sentido siguiente:

«3. En caso de que, como consecuencia del control realizado por la autoridad de destino, se detectara el incumplimiento de requisitos de acceso a la actividad de operadores o de normas de producción o requisitos del producto, se comunicará a la autoridad de origen (o a la autoridad del lugar de fabricación) para que esta adopte las medidas oportunas, incluidas las sancionadoras que correspondan».

76 El Dictamen del Consejo Económico y Social, de 18 de abril de 2013, sobre el Anteproyecto de Ley de Garantía de la Unidad de Mercado considera que el artículo 21 del texto configura una distribución de competencias que «debería aclararse o delimitarse con mayor precisión en aras a evitar posibles conflictos competenciales» (pág. 14).

77 Cfr. epígrafe f) de la Resolución de 14 de octubre de 2014, de la Secretaría General de Coordinación Autonómica y Local, por la que se publica el Acuerdo ya citado anteriormente. 
Si la propia Ley distingue entre autoridades de origen y autoridades del lugar de fabricación a efectos de supervisión y control, no se entiende que se cercene a estas últimas del posible ejercicio de la potestad sancionadora en el supuesto descrito por el apartado reproducido. Conforme al contenido literal actual del precepto, si una empresa tuvo su acceso en la Comunidad de Madrid y la autoridad valenciana detecta un incumplimiento de la normativa de producción de un producto fabricado por aquella en sus instalaciones de Córdoba, se tendría que dirigir a la autoridad competente de Madrid "para que esta adopte las medidas oportunas». Situación que no sólo es incongruente con lo dispuesto en el apartado 2.c) del propio artículo, conforme al que se atribuye a la autoridad andaluza la competencia de supervisión y control (que, a nuestro juicio, debería conllevar como apéndice necesario la potestad sancionadora) en dicho supuesto, sino que además sería en la práctica poco operativa, siendo así que es más eficaz que sea la autoridad del lugar donde se produce el incumplimiento la que inspeccione $\mathrm{y}$, en su caso, active las medidas correctoras y punitivas correspondientes.

Por otra parte, en relación con la mención que el apartado 3 del artículo 21 hace a los «requisitos del producto» conviene reiterar (en coherencia con lo mantenido en el apartado anterior) que cuando los incumplimientos detectados por la autoridad de destino sean relativos al "uso y consumo» de los mismos y a su comercialización, posiblemente se verá afectada la correspondiente normativa comercial o de consumo autonómica. En nuestra opinión, en los casos en que así fuera, la potestad sancionadora debe corresponder a las autoridades de destino competentes en materia de consumo y comercio donde se produzca el ejercicio de la actividad de comercialización del producto - precisamente porque se trata de requisitos de ejercicio-, sin que corresponda instar a la autoridad de origen para que sea esta la que ejercite dicha potestad. Así, aprovechando los ejemplos utilizados anteriormente, si el incumplimiento detectado por la autoridad valenciana relativo a los requisitos de uso y consumo de un producto - la oferta de productos caducados o en mal estado de conservación, por ejemploestuviera tipificado como infracción en su propia normativa en materia de consumo o comercial, sería dicha autoridad la competente para sancionar, sin que proceda desglosar las facultades de intervención sobre la actividad de la empresa concernida, adjudicando las potestades de supervisión y sancionadora a autoridades distintas, como parece apuntar la LGUM en este punto.

Supuesto distinto es el caso de que la autoridad de destino detecte algún incumplimiento relativo a los que anteriormente identificamos 
como requisitos estrictamente vinculados al acceso a la actividad del operador (básicamente, elementos subjetivos relacionados con la constitución formal de la empresa y garantías). Caso en el que sí cobra sentido la comunicación de dicha circunstancia a la autoridad de origen, siendo esta última la que estará en mejor disposición para su comprobación y, en su caso, adopción de las medidas correctoras y sancionadoras que correspondan ${ }^{78}$.

Así y todo, la aplicación práctica del supuesto anterior no queda exenta de eventuales problemas, pues si, como parece obvio, se refiere a operadores económicos que han accedido a la actividad en otra CA quedarán sometidos al cumplimiento de los requisitos de acceso vigentes en la misma, lo que presupone el conocimiento de la normativa de origen por parte de los órganos de inspección de la CA de destino para poder detectar los posibles incumplimientos a dicha normativa. Esto es, los órganos de control de la CA de destino, al supervisar la actividad de una empresa cuyo acceso ha tenido lugar en otra CA, aplican su propia normativa sólo en cuanto al ejercicio, no respecto a los requisitos de acceso que esta última normativa pudiera disponer, que no resultan de aplicación al operador. Ciertamente, la experiencia muestra que, frecuentemente, los requisitos de acceso establecidos por las distintas normativas autonómicas para el acceso a una misma actividad se asemejan, por lo que cabría suponer que los servicios de inspección de la autoridad de destino estarán capacitados para detectar su incumplimiento por similitud con los propios. Pero no puede dejar de observarse que en las ocasiones en que estos requisitos, por hipótesis, fueran muy diferentes, dichos servicios tendrían que detectar incumplimientos de una normativa ajena a su ámbito usual de actuación ${ }^{79}$; requisitos y normativa que, por otra parte, pueden incluso no existir, al amparo de lo previsto en el artículo 19 de la LGUM.

Por otra parte, conviene insistir en que, en ocasiones, alguno de los requisitos exigidos para el acceso a una actividad puede tener la consideración a su vez de requisito permanente vinculado al ejercicio de la actividad, como puede ser el caso de la cualificación profesional del personal. Así, en tanto el operador desarrolle su actividad de manera presencial (permanentemente a través de sucursales, o esporá-

78 El Informe del Consejo General del Poder Judicial sobre el Anteproyecto de la LGUM, de 11 de abril de 2013 (pág. 23), sin embargo, censura la «prevalencia manifiesta» que se confiere a las autoridades de origen en el sistema de supervisión previsto en el artículo 21, "hasta el extremo de poder sancionar comportamientos que se han desarrollado en el ámbito territorial de las autoridades de destino".

79 Alude también a esta posible dificultad M. J. Alonso Mas, cit., pág. 347. 
dicamente en determinados eventos) en el territorio de otra CA distinta de la de acceso y la normativa de esta última exija dicha cualificación como requisito de ejercicio de la actividad, podrá ser exigido por esta $\mathrm{y}$, en su caso, sancionado su incumplimiento por dicha autoridad de destino ${ }^{80}$. Y ello no sólo en virtud de lo dispuesto en el apartado 2.b) del artículo 21, sino también de la interpretación a sensu contrario del propio apartado 3 , del que cabe deducir que si, como consecuencia del control realizado por la autoridad de destino, se detecta un incumplimiento relativo a los requisitos de ejercicio, esta no tiene que comunicar nada, sino que debe aplicar su propia normativa y actuar en consecuencia ${ }^{81}$.

En resumen, frente a la denunciada parquedad del texto legal al respecto ${ }^{82}$, lo que se viene proponiendo es una interpretación coherente con la propia sistemática de la Ley, que pasa por considerar la potestad sancionadora como complemento necesariamente vinculado a las funciones de supervisión y control ${ }^{83}$.

Entendemos así que se deberían aplicar a la potestad sancionadora las mismas reglas de distribución expuestas para la determinación de la autoridad competente para el ejercicio de la función de supervisión, de modo que: a) la sanción del incumplimiento de requisitos relativos al acceso a la actividad corresponda a la autoridad de origen; b) la sanción del incumplimiento de requisitos concernientes al ejercicio de la actividad corresponda a la autoridad de destino; c) la del incumplimiento de requisitos relacionados con la producción debe corresponder a la autoridad del lugar de fabricación. En cada caso se debería aplicar,

80 Piénsese en el requisito de cualificación profesional requerida al personal encargado de la extracción de muestras en el caso, citado supra, de un laboratorio de análisis clínico con sede en una CA y sucursales en otra distinta. O la cualificación exigida a los monitores de una empresa de turismo activo que pueda desarrollar su actividad en una CA distinta a la de acceso.

81 Por el contrario, a B. Lozano CutAndA, «Ley 20/2013, de Garantía de la Unidad de Mercado: las diez reformas clave», Revista CESCO de Derecho de Consumo, núm. 9, 2014, pág. 161, le parece que uno de los problemas que va a generar la aplicación de la LGUM «será el derivado del hecho de que la competencia para sancionar al operador por los incumplimientos de los requisitos para el ejercicio de la actividad económica está residenciada en la autoridad de origen, pero quien en la práctica ejercerá su control será la autoridad de destino».

82 El Dictamen del Consejo Económico y Social, de 18 de abril de 2013, sobre el Anteproyecto de Ley de Garantía de la Unidad de Mercado recrimina que en el texto «no se especifica el procedimiento sancionador aplicable en caso de infracción de la norma, generando dudas, entre otros casos, cuando la normativa del lugar de prestación de un servicio difiera de la correspondiente al lugar de origen, redundando todo ello en una interpretación y en una aplicación compleja, a priori, de la norma» (pág. 9).

83 En línea con el mencionado considerando 106 de la Directiva de Servicios, para el que el término «supervisión» debe abarcar actividades tales como «controles e indagaciones, resolución de problemas, ejecución e imposición de sanciones y las consiguientes actividades de seguimiento». 
obviamente, la normativa propia en materia de acceso, ejercicio de la actividad o fabricación de productos, respectivamente ${ }^{84}$.

\section{REFLEXIÓN FINAL}

En síntesis, el sistema de supervisión administrativa analizado guarda una conexión evidente con el principio de eficacia de las actuaciones de las autoridades competentes en todo el territorio nacional, constituyendo en cierto modo la instrumentación del mismo o, como se ha dicho, el «envés» de los preceptos que articulan dicho principio de eficacia ${ }^{85}$. En este último aspecto se han centrado especialmente las críticas de la doctrina, muy específicamente en la regulación del alcance de los efectos de las actuaciones administrativas propias del control de acceso a las actividades económicas, atendiendo a dicho principio de eficacia.

Pero también el sistema de supervisión administrativa presenta un nexo coherente con los principios de cooperación, confianza mutua y de simplificación de cargas dispuestos por la propia LGUM. Es evidente que la Ley incurre en determinados excesos, pero en punto a la supervisión marca el camino conveniente incluso para el hipotético caso futuro de que se optara por los mecanismos de armonización en positivo que se han apuntado.

Seguramente, el nuevo sistema, inspirado en la que podríamos calificar como regla de supervisión por la Administración más cercana, puede suponer una reducción de cargas administrativas para los operadores, a la par que una simplificación de las actividades de las Administraciones públicas, por lo que debería contribuir a evitar duplicidades. El esquema parece así en principio razonable y su aplicación, en cuanto sea capaz de incrementar la eficacia administrativa y reducir costes para los agentes económicos y también para la Administración, podría contribuir ligeramente a la mejora de la competitividad empresarial.

84 Junto a las reglas de determinación de la autoridad competente para la supervisión examinadas, el capítulo VI de la LGUM establece dos instrumentos orientados a facilitar dicha función (una base de datos sectorial común junto a un sistema de intercambio electrónico de datos) que, por razones de extensión, no ha sido posible abordar. No obstante, queremos dejar constancia al menos de que en la reunión constitutiva del Consejo para la Unidad de Mercado (27 de enero de 2015) se ha estudiado la implantación de varias plataformas informáticas para facilitar la aplicación de la LGUM, entre las que se encuentra la Plataforma de registros integrados sectoriales y la Plataforma de comunicaciones y supervisión, «donde todas las Administraciones podrán solicitar información de otra Administración» (información difundida en www.minhap.gob.es, febrero de 2015).

85 Cfr. Dictamen 193/2014, de 19 de marzo, del Consejo Consultivo de Andalucía, FJ III.7. 
Dicho sea lo anterior, la aplicación del sistema requiere superar ciertas dificultades que se han venido señalando en el presente trabajo, bastando en algunos casos la vía interpretativa - como en los casos de confusión en el léxico-, pero requiriendo en otros una modificación legal, muy especialmente en lo relativo a la libertad del operador de escoger la autoridad de origen de supervisión (disposición adicional décima). No parece arriesgado vaticinar la generación de una significativa conflictividad en la aplicación práctica de determinados aspectos de la LGUM (algunos inéditos hasta ahora), de no solucionar los problemas detectados ${ }^{86}$.

Por otra parte, frente a la denunciada restricción del ámbito de disposición de las autoridades competentes para la fijación de requisitos de acceso a las actividades económicas y la augurada potencial regulación a la baja de los mismos, conviene retener la mayor flexibilidad dispensada al tratamiento de los requisitos vinculados al ejercicio de las actividades. La existencia de requisitos dispares relativos al ejercicio de las actividades económicas en principio no vulnera la LGUM, siempre que respeten los principios de necesidad para la salvaguarda de alguna razón imperiosa de interés general y de proporcionalidad para su consecución.

Ciertamente, en ocasiones dicha disparidad podrá generar disfunciones, como se ha puesto de manifiesto en algunos de los casos planteados ante la SECUM a través del procedimiento de información previsto en el artículo 28 de la Ley, que deberían ser abordadas a través de los mecanismos de cooperación previstos en el capítulo III de la LGUM $^{87}$ y, cuando se considere necesario, activando la competencia estatal recogida en el artículo 149.1.13. ${ }^{a} \mathrm{CE}$ o recurriendo a leyes de armonización, tal como ha sido propuesto por la doctrina.

Junto a la aludida labor institucional, en la que resultará determinante la intervención del Consejo para la Unidad de Mercado y de las Conferencias Sectoriales, el funcionamiento efectivo del sistema de supervisión administrativa dispuesto por la LGUM necesitaría para su realización de una buena dosis de leal y estrecha cooperación en el día a día de su actividad por parte de las Administraciones públicas, lo que, lamentablemente, no viene siendo hasta el momento su tónica de actuación.

86 Las previsiones de conflictividad en la aplicación práctica de algunos aspectos de la LGUM son frecuentes; entre otros, J. Tornos Mas, cit., pág. 167; C. Padrós Reig y J. M. Macías Castaño, cit., pág. 150; o B. Lozano Cutanda, cit., pág. 161.

87 Cooperación a la que remiten varios de los informes de la SECUM, como el informe de 4 de noviembre de 2014, sobre «Seguros-Hojas de reclamaciones»; el de 29 de octubre de 2014, sobre «Sanidad-Carteles prohibido fumar», o el de 4 de junio de 2014, sobre "TurismoClasificación de hoteles». 